\title{
Sox2 and Jagged1 Expression in Normal and Drug-Damaged Adult Mouse Inner Ear
}

\author{
Elizabeth C. Oesterle, ${ }^{1}$ Sean Campbell, ${ }^{1}$ Ruth R. Taylor, ${ }^{2}$ Andrew Forge, ${ }^{2}$ \\ AND Clifford R. Hume ${ }^{1,3}$ \\ ${ }^{1}$ Virginia Merrill Bloedel Hearing Research Center, Department of Otolaryngology—Head and Neck Surgery, \\ University of Washington, CHDD CD176 Box 357923 Seattle, WA 98195-7923, USA \\ ${ }^{2}$ Center for Auditory Research, UCL Ear Institute, 332 Gray's Inn Road, London, WC1X8EE, UK \\ ${ }^{3}$ VA Puget Sound Health Care System, Seattle, WA 98108, USA
}

Received: 25 June 2007; Accepted: 25 October 2007; Online publication: 22 December 2007

\begin{abstract}
Inner ear hair cells detect environmental signals associated with hearing, balance, and body orientation. In humans and other mammals, significant hair cell loss leads to irreversible hearing and balance deficits, whereas hair cell loss in nonmammalian vertebrates is repaired by the spontaneous generation of replacement hair cells. Research in mammalian hair cell regeneration is hampered by the lack of in vivo damage models for the adult mouse inner ear and the paucity of cell-type-specific markers for nonsensory cells within the sensory receptor epithelia. The present study delineates a protocol to drug damage the adult mouse auditory epithelium (organ of Corti) in situ and uses this protocol to investigate Sox2 and Jagged1 expression in damaged inner ear sensory epithelia. In other tissues, the transcription factor Sox2 and a ligand member of the Notch signaling pathway, Jagged1, are involved in regenerative processes. Both are involved in early inner ear development and are expressed in developing support cells, but little is known about their expressions in the adult. We describe a nonsurgical technique for inducing hair cell damage in adult mouse organ of Corti by a single high-dose injection of the aminoglycoside kanamycin followed by a single injection of
\end{abstract}

Correspondence to: Elizabeth C. Oesterle · Virginia Merrill Bloedel Hearing Research Center, Department of Otolaryngology-Head and Neck Surgery · University of Washington - CHDD CD176 Box 357923 Seattle, WA 98195-7923, USA. Telephone: +1-206-6162705; fax: +1-206-2215685; email: oesterle@u.washington.edu the loop diuretic furosemide. This drug combination causes the rapid death of outer hair cells throughout the cochlea. Using immunocytochemical techniques, Sox2 is shown to be expressed specifically in support cells in normal adult mouse inner ear and is not affected by drug damage. Sox 2 is absent from auditory hair cells, but is expressed in a subset of vestibular hair cells. Double-labeling experiments with Sox2 and calbindin suggest Sox2-positive hair cells are Type II. Jagged 1 is also expressed in support cells in the adult ear and is not affected by drug damage. Sox2 and Jagged1 may be involved in the maintenance of support cells in adult mouse inner ear.

Keywords: ototoxicity, aminoglycoside, cochlea, vestibular, supporting cell, hair cell

Abbreviations: $\mathrm{HC}$ - hair cell; IHC - inner hair cell; OHC - outer hair cell; SC - support cell; SE - sensory epithelia

\section{INTRODUCTION}

Inner ear hair cells (HCs) are mechanoreceptors that detect environmental signals associated with hearing, balance, and body orientation. Unfortunately, HCs are killed by a variety of mechanisms, including loud sounds, ototoxic drugs, and aging. As HCs are lost, function deteriorates. Nonmammalian vertebrates are able to replace the lost HCs via two processes: the cell division of resident progenitor/stem cells and the direct conversion of another cell type (e.g., support 
cells [SCs]) into HCs without an intervening mitosis (Corwin and Cotanche 1988; Ryals and Rubel 1988; Adler and Raphael 1996; Baird et al. 1996; Roberson et al. 1996, 2004; Taylor and Forge 2005). Humans and other mammals, in contrast, are unable to replace lost auditory HCs and have limited ability to regenerate vestibular HCs (reviewed in Bermingham-McDonogh and Rubel 2003; Oesterle and Stone 2008). In mammals, HC loss typically leads to the formation of sensory epithelial scars by SCs that remain in the epithelium and irreversible hearing and balance deficits.

A critical question is why robust HC replacement does not occur in the mature mammalian inner ear after damage. Mice are a powerful model system for many disease and damage processes, because of the abundance of antibodies, probes, and genetic mutants available. A mouse model of aminoglycoside-induced deafness will help to unravel the question as to why mammals have a limited ability to regenerate HCs. Unfortunately, lesioning the adult mouse cochlea has proved to be considerably more difficult than lesioning other rodents such as guinea pig or chinchilla (previous major animal models for aminoglycosideinduced hearing loss, as well as noise-induced hearing loss). Adult mice have shown little drug-induced toxicity under conditions that would produce severe auditory damage in the guinea pig or chinchilla (Forge and Schacht 2000). Existing damage protocols require repeated systemic injections of aminoglycoside to achieve HC damage (Henry et al. 1981; Chen and Saunders 1983; Wu et al. 2001; Jiang et al. 2005, 2006a, b; Chu et al. 2006; Staecker et al. 2007). Because these protocols result in a desynchronized loss of HCs, they do not allow studies of critical early regenerative events. Furthermore, the HC damage is frequently limited to a portion of the cochlea that is particularly difficult to access and examine morphologically, the basal region where high-frequency sound information is encoded (Forge and Schacht 2000; Wu et al. 2001). Topical ototoxicity protocols for mice have included application of aminoglycosides via trans-tympanic injection and placement of aminoglycoside-soaked Gelfoam in the round window niche (Heydt et al. 2004; Staecker et al. 2007). These methods are cumbersome, involve surgery, and typically produce variable lesions restricted to the basal region of the cochlea. We present a reliable nonsurgical approach for inducing HC damage in the adult mouse auditory epithelium, the organ of Corti, by a single high-dose injection of aminoglycoside potentiated by a single injection of a loop diuretic. This protocol results in the rapid death of outer HCs along virtually the entire length of the cochlea.

Research in mammalian HC regeneration has also been hampered by the paucity of cell-type-specific markers for non-sensory SCs in mature mammalian inner ear receptor epithelia. The identification of SC-specific markers for the adult mouse ear will assist toward characterizing and understanding the responsiveness of mammalian SCs to HC death. Non-sensory SCs serve as progenitors to regenerated HCs in nonmammalian ears and in the adult mammalian vestibular sensory epithelia (SE; reviewed in Matsui and Cotanche 2004; Matsui et al. 2005; Oesterle and Stone 2008). Under certain experimental circumstances, SCs in neonatal organ of Corti can give rise to new HCs via mitotic pathways (Chen and Segil 1999; Löwenheim et al. 1999; Mantela et al. 2005; Sage et al. 2005; White et al. 2006) or by the non-mitotic conversion of SCs into HCs upon altering Notch signaling with $N$-S-phenyl-glycine- $t$-butyl ester (DAPT: an inhibitor of gamma secretase: Woods et al. 2004; Yamamoto et al. 2006). SCs can be converted into HCs upon transfection of the developmental gene Atoh1 (Math1, Zheng and Gao 2000; Shou et al. 2003; Woods et al. 2004; Izumikawa et al. 2005). For this reason, it is of considerable interest to better understand the SC phenotypes, how their differentiation is specified and maintained in the adult ear, how they respond to HC death, and whether they need to undergo partial dedifferentiation for a regenerative process to occur. We describe the expression pattern of two molecules, Sox2 and Jagged1, that distinguish the SC phenotype in developing mammalian inner ear sensory receptor epithelia. SCs in developing mouse inner ear express Sox2 and Jagged1, but their expression patterns in the adult remain to be characterized (e.g., Wood and Episkopou 1999; Woods et al. 2004; Kiernan et al. 2005a, b, 2006).

Sox2, a SRY-related HMG box transcription factor and a member of the Group B subgroup of Sox genes (Sox1, Sox2, Sox3), is involved in neurogenesis and in the proliferation and/or maintenance of stem cells, including neural stem cells (reviewed in Episkopou 2005; Wegner and Stolt 2005). In the ear, Sox2 appears to be required for the development of the sensory domains (Kiernan et al. 2005a, b). Sox2 marks sensory progenitors early in inner ear development and acts upstream of the Atoh1 gene during sensory organ formation (Kiernan et al. 2005a, b). Its role in later cell differentiation events is unknown. Mutations in the Sox2 gene result in severe malformations of inner ear end organs, missing HCs and SCs, and impaired hearing (Hagstrom et al. 2005; Kiernan et al. 2005a, b). In light of Sox2's being a distinguishing marker for stem and progenitor cells in other systems and evidence suggesting the presence of stem/ progenitor cells in mature mammalian inner ear SE (Warchol et al. 1993; Malgrange et al. 2002; Li et al. 2003a, b; Lopez et al. 2004; Oshima et al. 2007; Savary et al. 2007), we examined Sox2 expression in normal and drug-damaged adult mouse inner ear SE. 
Jagged1 (referred to as Serrate 1 in chick and SerrateA or Jagged $1 b$ in zebrafish) is a member of the Notch signaling pathway, a pathway known to play a pivotal role in the differentiation of HCs and SCs (reviewed in Kelley 2006a, b). Jagged1 is expressed in prosensory regions of the ear before cell differentiation (Adam et al. 1998; Morrison et al. 1999; Kiernan et al. 2006). Like Sox2, Jagged1 signaling is required for the development of inner ear sensory organs (Kiernan et al. 2006). It subsequently becomes restricted to the SCs, and its expression is maintained in auditory and vestibular SCs through the early postnatal period (Zine et al. 2000; Woods et al. 2004). Its expression in the adult mammalian ear has not been well characterized, but it is known to be present in posthatch avian inner ear SE (Stone and Rubel 1999). Activation or reactivation of Notch signaling in adult organs may be important to form new cells during regenerative events. Notch signaling is thought to be involved in the postembryonic replacement of HCs in the chicken inner ear (Stone and Rubel 1999), and activation of Jagged1/Notch signaling in adult rat liver appears to contribute to the regeneration of this organ after damage (Köhler et al. 2004). We examined Jagged1 expression in the adult mouse inner ear.

The present study outlines a systemic protocol to kill HCs in vivo in the organ of Corti of adult mice and uses this protocol to investigate $\mathrm{SC}$ responsiveness to HC death as assayed by Sox 2 and Jagged1 expression. We show that the aminoglycoside kanamycin and the loop diuretic furosemide rapidly kill outer hair cells (OHCs) throughout the adult cochlea. Sox2 is expressed specifically in auditory and vestibular SCs and in a subset of vestibular HCs. After aminoglycoside damage, Sox2 expression is maintained in SCs in the organ of Corti. Jagged1 also is expressed in adult SCs and is unaffected by damage. Preliminary accounts of portions of these data have been presented in abstract form (Oesterle et al. 2007).

\section{MATERIALS AND METHODS}

\section{Animals}

The Institutional Animal Care and Use Committee at the University of Washington approved experimental methods and animal care procedures. Adult mice (420 weeks old; outbred Swiss Webster [Harlan, Indianapolis, IN, USA] and inbred CBA/Caj [Jackson Laboratory, Bar Harbor MA] strains) were killed by cervical dislocation or by anesthesia with $\mathrm{CO}_{2}$ followed by cervical dislocation. Postnatal day (P) 1-5 mice were killed by decapitation. Posthatch chickens (P7-P10) were used for a few experiments. Fertilized eggs or 1-day-old hatchings of White Leghorn chick- ens were received from Hyline (Graham, WA). Eggs were placed in a humidified incubator at $37^{\circ} \mathrm{C}$ until hatching. Hatchlings were housed in heated brooders with ample food and water in the Animal Care Facility at the University of Washington until killed by overdose of pentobarbital and decapitation.

\section{Drug-lesioning paradigm}

HC death was experimentally induced in mice by administering single doses of kanamycin $(1,000 \mathrm{mg} / \mathrm{kg}$, dissolved in phosphate-buffered saline [PBS], SigmaAldrich Co., St. Louis, MO, USA, Cat. No. K-1377, subcutaneous) followed $30-45$ min later by a single dose of furosemide $(400 \mathrm{mg} / \mathrm{kg}$, Hospira Inc., Lake Forest, IL, USA, Cat. No. RL-1206, intraperitoneal). Animals were killed 1, 2, 3, 7, 14, 28-30, 80, 365 days after the injections. Age-matched animals, not injected with the drug combination, were used as controls.

For some experiments, repeated series of the drugs were given once per day for up to 5 days.

\section{Tissue preparation}

\section{Adults}

The temporal bones from adult mice were dissected free. After removal of the bulla, the stapes was lifted from the oval window, and small openings were made in the apical and basilar turns. For experiments involving immunofluorescence processing, cold $4 \%$ paraformaldehyde in $0.1-\mathrm{M}$ phosphate buffer, $\mathrm{pH}$ 7.4, was perfused slowly through the cochlea, after which the temporal bones were kept in the same fixative for $4 \mathrm{~h}$ at room temperature. After fixation, the temporal bones were washed three times (10 min each) in PBS ( $\mathrm{pH} 7.4)$. The tissue was prepared as whole-mount preparations or cryostat sections (Oesterle et al. 1990). For the former, segments (half turns) of the organ of Corti were carefully dissected free from the cochlea. The stria vascularis was pulled off or trimmed down, and the tectorial membrane was lifted free with fine forceps and then discarded. Whole-mount preparations of the utricle were prepared by isolating the utricle from the temporal bone and removing the otoconia by directing a stream of PBS across the utricle from a syringe with a fine gauge needle. For cryosections, the temporal bones of adult mice were decalcified with RDO Rapid Decalcifier (Apex Engineering Products Corp., Aurora, IL, USA) at room temperature for $15 \mathrm{~min}$, rinsed in PBS, and sequentially infiltrated with sucrose $(10 \%$ for $30 \mathrm{~min}, 15 \%$ for $30 \mathrm{~min}, 1: 1$ mix $15 \%$ sucrose/O.C.T. overnight) and O.C.T. compound (Tissue Tek, Sakura Finetek Inc., Torrance, 
CA, USA), frozen rapidly with dry ice, and cut into $12-\mu \mathrm{m}$ sections with a cryostat. Sections were mounted onto Platinum Superfrost (+) slides (Mercedes Medical).

A few ears were prepared for plastic embedding and sectioning. For this, an intralabyrinthine perfusion was performed with $3.5 \%$ glutaraldehyde in $0.1 \mathrm{M}$ potassium phosphate buffer ( $\mathrm{pH} 7.4$ ), and the temporal bones were immersed in this fixative overnight at $4^{\circ} \mathrm{C}$. After washes with PBS, the ears were decalcified with RDO Rapid Decalcifier at room temperature for $15 \mathrm{~min}$, rinsed in PBS, and dehydrated in a graded ethanol series $(35 \%$ for $15 \mathrm{~min}, 70 \%$ overnight, $95 \%$ for $15 \mathrm{~min}, 100 \%$ for $15 \mathrm{~min}$ ). Tissues were then incubated in propylene oxide, before embedding in Eponate 12 resin (Ted Pella Inc., Redding, CA, USA). Semithin sections were cut at a thickness of $2 \mu \mathrm{m}$ through the organ and mounted onto acid-washed, chrome-alum-subbed slides. Slides were counterstained with $1 \%$ toluidine blue before coverslipping with DPX mounting medium.

\section{Neonatals}

The brains from neonatal mice were removed, and the heads were immersed in fixative (4\% paraformaldehyde in $0.1 \mathrm{M}$ phosphate buffer, $\mathrm{pH}$ 7.4) for $4 \mathrm{~h}$. After washes in PBS, the temporal bones were dissected free and processed as whole-mount preparations as described earlier.

\section{Chickens}

Chicks were killed by pentobarbital overdose $(100 \mathrm{mg} / \mathrm{kg}$; intraperitoneal injection) and decapitated. Individual ears were fixed by intralabyrinthine perfusion with $4 \%$ paraformaldehyde (0.1 M phosphate buffer, $\mathrm{pH} 7.4)$. Heads were immersed in fixative for $1-4 \mathrm{~h}$ at room temperature. They were then washed with PBS, and cochlear ducts and utricles were isolated and prepared as whole-mount preparations or cryostat sections as described above, with the exception that the decalcification step was omitted.

\section{Antibodies}

The following antibodies were used to label HCs in neonatal and adult mice: a mouse monoclonal antiparvalbumin antibody (parv19, Cat. No. P3088, Sigma, 1:1000; Sage et al. 2000), a rabbit anti-pig myosin 6 polyclonal antibody (from Dr. Tama Hasson, University of California-San Diego, or Proteus Biosciences, Ramona, CA, USA, Cat. No. 25-6791, 1:500; Hasson and Mooseker 1994; Hasson et al. 1997), and a rabbit anti-human myosin 7a (from Dr. Tama Hasson or Proteus Biosciences, Cat. No. 25-6790, 1:500; Hasson et al. 1995, 1997). All of these antibodies have been used previously to label HCs in mice and other mammals (e.g., Hasson et al. 1997; Sage et al. 2000; Montcouquiol and Kelley 2003; Hackney et al. 2005).

To label afferent calyx and dimorphic fibers in the striola and juxtastriola regions of the otolithic organs, an anti-calbindin antibody (Cat. No. AB1778, Chemicon, now part of Millipore, Temecula, CA, USA) was used at a dilution of 1:250 (Dechesne et al. 1994; Dechesne and Thomasset 1988). This antibody has been used previously in mice to delineate the striolar region (e.g., Cunningham et al. 2002).

Two antibodies were used to detect Sox2. A rabbit anti-Sox2 affinity purified polyclonal antibody directed against human Sox2 was purchased from Chemicon/Millipore (Cat. No. AB5603) and used at 1:1000. This antibody has been used on mouse (Ferri et al. 2004; Kiernan et al. 2006), and Western blot analyses carried out by the manufacturer on murine samples demonstrated that this antibody, at lower concentrations, recognizes a single protein of the correct size, approximately $34 \mathrm{kDa}$. The second anti-Sox2 antibody, an affinity purified goat polyclonal antibody directed against the C-terminus of human Sox2, was purchased from Santa Cruz (Sox-2 Y-17, Cat. No. SC17320, Santa Cruz, CA, USA). The Y-17 antibody was used routinely at dilutions of 1:500-1:1000. Specificity of the Y-17 antibody was verified by blocking with a Sox2-specific peptide. Preincubating the Y-17 primary antibody with a tenfold excess (by weight) of the immunizing peptide eliminates all labeling (Hume et al. 2007). The Y-17 antibody stained a single band of 37-40 kDa on Western blot (manufacturer's technical information). The same labeling pattern was seen in the inner ear with both anti-Sox2 antibodies.

The following 2 antibodies were used to detect Jagged1: Jagged1 (H-114) and Jagged1 (C-20), both from Santa Cruz Biotechnology, Inc. Jagged1 (H-114; Cat. No. SC-8303) is a rabbit polyclonal raised against amino acids 1110-1223 of human Jagged1, and it was used at 1:100. Western blot analyses carried out by the manufacturer on murine samples have demonstrated that this antibody, as well as the anti-Jagged1 (C-20) antibody discussed below, does not cross-react and recognizes a single protein of the correct size $(150 \mathrm{kDa}$ molecular weight). Others have used the $\mathrm{H}-114$ antibody in mouse inner ear (Zine and de Ribaupierre 2002; Woods et al. 2004; Kiernan et al. 2006; Jones et al. 2006). Jagged1 (C-20; Cat. No. SC-6011) is an affinity purified goat polyclonal antibody raised against the C-terminus of human Jagged1. It was used at dilutions of $1: 100$ to 1:1000. Jagged 1 (C-20) was used previously in mouse inner ear (Morrison et al. 1999; Chen et al. 2002; Brooker et al. 2006). The same labeling pattern was seen with both anti-Jagged1 antibodies in whole-mount preparations of utricular 
and saccular macula. In cryostat sections of adult inner ear, H-114 labeling was not detectable, probably because of antibody sensitivity to the decalcification process. The C-20 antibody labeling, on the other hand, was retained.

\section{Phalloidin labeling}

To label HCs and visualize SCs and SC scars, phalloidin conjugated to a fluorophore (Alexa 594, Invitrogen Corp., Eugene, OR, USA, Cat. No. A12381) was added to whole-mount preparations of isolated inner ear end organs at a concentration of 5 units/ml (approx. $0.165 \mu \mathrm{M})$. After a 30-min incubation at room temperature, the tissue was washed in PBS $(3 \times 10 \mathrm{~min})$ and mounted on a microscope slide in Vectashield.

\section{Immunofluorescent staining}

The tissue was treated for $30 \mathrm{~min}$ with $0.1 \%$ saponin $/ 0.1 \%$ Tween 20 in PBS to make membranes more permeable to antibodies. To prevent nonspecific binding of the primary antibody, tissues were then incubated for $1 \mathrm{~h}$ in a blocking solution consisting of $10 \%$ normal serum $/ 0.03 \%$ saponin/0.1\% Triton X-100 in PBS. Primary antibody incubations were performed for 1 day at $4^{\circ} \mathrm{C}$ in PBS, $0.03 \%$ saponin, $3 \%$ serum, $2 \mathrm{mg} / \mathrm{ml}$ bovine serum albumin, and $0.1 \%$ Triton X-100. Fluorescent-labeled secondary antibodies (Alexa 488, 568, 594, Invitrogen/Molecular Probes) were used at a dilution of 1:200 in the same buffer for 2-4 h (at room temperature) or overnight (at $4^{\circ} \mathrm{C}$ ). In some cases (for Myosin 6,7a), the tyramide signal amplification (TSA) system (Invitrogen/Molecular probes) was used for signal amplification as recommended by the manufacturer. For mouse antibodies against parvalbumin, the Mouse-on-Mouse kit (M.O.M.) was used as specified by the manufacturer (Vector Labs). Sections were washed after each antibody incubation (three times for $10-15$ min each) in $0.1 \%$ Tween 20 in PBS. After counterstaining nuclei with bisbenzimide (Cat. No. H1398, Molecular Probes, Eugene, OR, USA, $0.5 \mu \mathrm{g} / \mathrm{ml}$ ), 4', 6-diamidine-2-phenylindole (DAPI; Cat. No. D9542, Sigma-Aldrich, $1 \mu \mathrm{g} / \mathrm{ml}$ ), propidium iodide (Cat. No. P1304, Invitrogen Corp., $1 \mu \mathrm{g} / \mathrm{ml}$ ), or YO-PRO-1 (Cat. No. Y3603, Invitrogen Corp., 1:200), specimens were mounted in Vectashield (Vector Laboratories), coverslipped, and examined with either epifluorescence or confocal fluorescence microscopy. At least three individual animals, representative of each experimental paradigm, were analyzed for each antibody.

\section{Controls for immunofluorescence}

Method and antibody specificity were checked by (1) substituting nonimmune sera for the primary antibody, (2) using a series of dilutions of the primary antibody; and (3) processing positive control tissues alongside the adult inner ear tissue. Jagged1 and Sox2 have distinct tissue expression profiles in developing inner ear, and the specificity of the anti-Jagged 1 and Sox2 antibodies has been demonstrated in developing mouse inner ear (Chen et al. 2002; Zine and de Ribaupierre 2002; Woods et al. 2004; Brooker et al. 2006; Kiernan et al. 2005a, 2006). Hence, P1-P5 inner ear tissue served as positive control tissue for these antibodies. In double-labeling experiments, antibodies raised in different species were used to avoid crossreactivity among secondary antibodies.

\section{Microscope imaging}

Whole-mount organ of Corti, saccule, or utricle preparations were viewed under epiflourescence on a Zeiss Axioplan 2ie compound microscope, and images were captured with a Photometrics CoolSNAP hq digital camera (Image Processing Solutions, North Reading, MA, USA). Slidebook 4.0.1.40 (Intelligent Imaging Innovations, Denver, CO, USA) acquisition and processing software was used to acquire digital images and convert them to tagged image file format (TIFF) files. TIFF files were subsequently processed in Image and/or Adobe Photoshop 7 (Adobe, Seattle, WA, USA). For laser scanning confocal microscopy, we used an Olympus FV-1000, equipped with 405-nm blue diode, 457-, 488-, and 514-nm multiline argon, 543-nm helium neon green, and 637-nm helium neon red lasers. Fluoview version 1.4a acquisition software was used. Sequential image acquisition was performed when bleed-through between channels was an issue. Files were imported into ImageJ and/or Adobe Photoshop for processing and analysis.

Data analysis: estimation of number of Sox2-positive nuclei in whole-mount preparations

Whole-mount preparations of four utricles that were double labeled to detect Sox2 and calbindin and counterstained with bisbenzimide were examined with an Olympus FV-1000 confocal laser scanning microscope. Digital images were generated from $Z$ series (1- $\mu \mathrm{m}$ steps oriented parallel to the lumen) through the SE at $\times 60(\times 20$, zoom $=3)$ or $\times 100(\times 20$, zoom $=5)$. Eight-to-nine confocal $Z$ series were collected from each utricle; four to five regions were randomly selected from the extrastriolar region and four regions from the striolar/juxtastriolar region. One or two rectangular regions were then delineated within each confocal $Z$ series; the area of the delineated region was quantified with ImageJ, and density estimates of the following were determined using the Cell Counter plug-in for Image J: (1) number of Sox2-positive nuclei 
in the $\mathrm{HC}$ layer surrounded by calbindin-positive nerve fibers (Sox2+/Calbindin+), (2) number of Sox2-positive nuclei in the HC layer not surrounded by calbindin-positive nerve fibers (Sox2+/Calbindin-), (3) number of Sox2-negative nuclei in the HC layer surrounded by calbindin-positive nerve fibers (Sox2-/ Calbindin+), and (4) number of Sox2-negative nuclei in the HC layer not surrounded by calbindin-positive fibers (Sox2-/Calbindin-). Nuclei within the rectangle or touching its lower right and bottom borders were included in the counts. Average numbers, expressed as a function of SE area, were determined for the extrastriolar and striolar/juxtastriolar regions of each organ. For example, the average number of Sox2+/Calbindin+ cells (in the $\mathrm{HC}$ layer) per $100 \mu \mathrm{m}^{2} \mathrm{SE}$ was determined for the extrastriolar and striolar/juxtastriolar regions of each utricle. Mean values were determined for each paradigm.

For each utricle, the areas of the regions used for the analysis were totaled, and the proportion of the utricular macula that was sampled was calculated. Fifty-two to $57 \%$ of the striolar region was sampled for these analyses, and 32 to $43 \%$ of the extrastriolar region was sampled.

\section{Statistics}

Significance values were determined with the Student's test (Excel).

\section{RESULTS}

HC-specific markers for normal adult mouse inner ear SE

The adult auditory epithelium, the organ of Corti, is composed of two types of HCs (inner and outer HCs), a variety of SCs (Hensen, Deiters', inner pillar, outer pillar, inner phalangeal, and border cells), and the terminal portions of cochlear nerve fibers. In surface views of whole-mounted adult cochlea (Fig. 1), parvalbumin, myosin 6, and myosin 7a label the cytoplasm of inner hair cells (IHCs) and OHCs. Parvalbumin, a $\mathrm{Ca}^{2+}$-binding protein, is also observed in nerve terminals, nerve fibers, and spiral ganglion cell bodies. Parvalbumin, myosin 6, and myosin $7 \mathrm{a}$ have been shown previously to be selectively expressed in inner ear HCs (Dechesne et al. 1994; Hasson et al. 1995, 1997; Zheng and Gao 1997; Hackney et al. 2005).

\section{Summary of lesion characteristics; OHCs} throughout the cochlea are killed

Mice are the predominant model organism for hearing research because of the availability of numerous
FIG. 1. Normal adult mouse organ of Corti labeled with HC-specific markers. All images in the figure are taken from whole-mount preparations of the apical turn of the adult mouse cochlea. In the auditory epithelia, the HCs are distributed along the luminal surface of the epithelium, and their cell bodies do not make contact with the basal lamina. Support cells are interposed between HCs, and their cell bodies typically extend the entire depth of the epithelium, from the lumen to the basal lamina. Support cell nuclei reside primarily within the basal half of the epithelium, whereas $\mathrm{HC}$ nuclei reside in the luminal half. Parvalbumin (A), myosin 6 (B), and myosin 7a (C) label the cytoplasm of inner and outer hair cells in the normal (undamaged) adult mouse cochlea. Occasional outer hair cells $(\mathrm{OHCS})$ are missing in the apical turns (e.g., arrows in $\mathbf{B}, \mathbf{C})$. Brightest point projections from confocal $Z$ series spanning the full depth of the sensory epithelium are shown in parts $(\mathbf{B}-\mathbf{C})$ and the inset for part (A). IHCs Inner hair cells; SG spiral ganglion neurons; PI propidium iodide. Scale bar $=200 \mu \mathrm{m}$ in $(\mathbf{A})$ and $20 \mu \mathrm{m}$ in $(\mathbf{B}, \mathbf{C})$ and inset in $(\mathbf{A})$.

genetic models of disease and molecular tools for analysis. Our objective was to establish a rapid systemic protocol for the synchronous elimination of sensory HCs in adult mice. Based on experiments done in other mammals combining aminoglycosides with a loop diuretic (e.g., Bryant et al. 1987), we used a sequential combination of an aminoglycoside and a loop diuretic, to reliably eliminate OHCs along the entire length of the adult mouse cochlea. Our protocol consists of a single subcutaneous injection of the aminoglycoside kanamycin (1,000 mg/kg) followed 30 to $45 \mathrm{~min}$ thereafter with a single intraperitoneal injection of the loop diuretic furosemide $(400 \mathrm{mg} / \mathrm{kg})$, and this is defined herein as an "injection set." The extent and defining characteristics of the lesion were assessed and verified with three separate methods: (1) phalloidin labeling in whole-mount preparations, (2) HC-specific cytoplasmic labeling with antibody markers in whole-mount preparations, and (3) histological analysis in transverse semi-thin plastic sections of the cochlea.

In the normal ear, phalloidin labels F-actin in HCs and SCs. After damage, phalloidin also allows for the visualization and identification of SC scars that form as a consequence of HC loss (Raphael and Altschuler 1991). Although phalloidin labeling is a fast and easy means to identify HC loss, it is not definitive because an absence of cilia does not always accurately reflect the loss of underlying HC bodies (Sobkowicz et al. 1992, 1995, 1997; Zheng et al. 1999). Hence, we also used the HC-specific antibodies parvalbumin, myosin 6, and myosin 7a to visualize HC loss. Control experiments were conducted at several recovery time points to verify that the loss of a HC marker (e.g., parvalbumin or myosin) was indicative of actual HC loss. For these experiments, HCs were double labeled with two HC markers (e.g., parvalbumin and myosin 6) and counterstained with a nuclear marker. The absence of single-labeled HCs and nuclei in the HC layer in the 

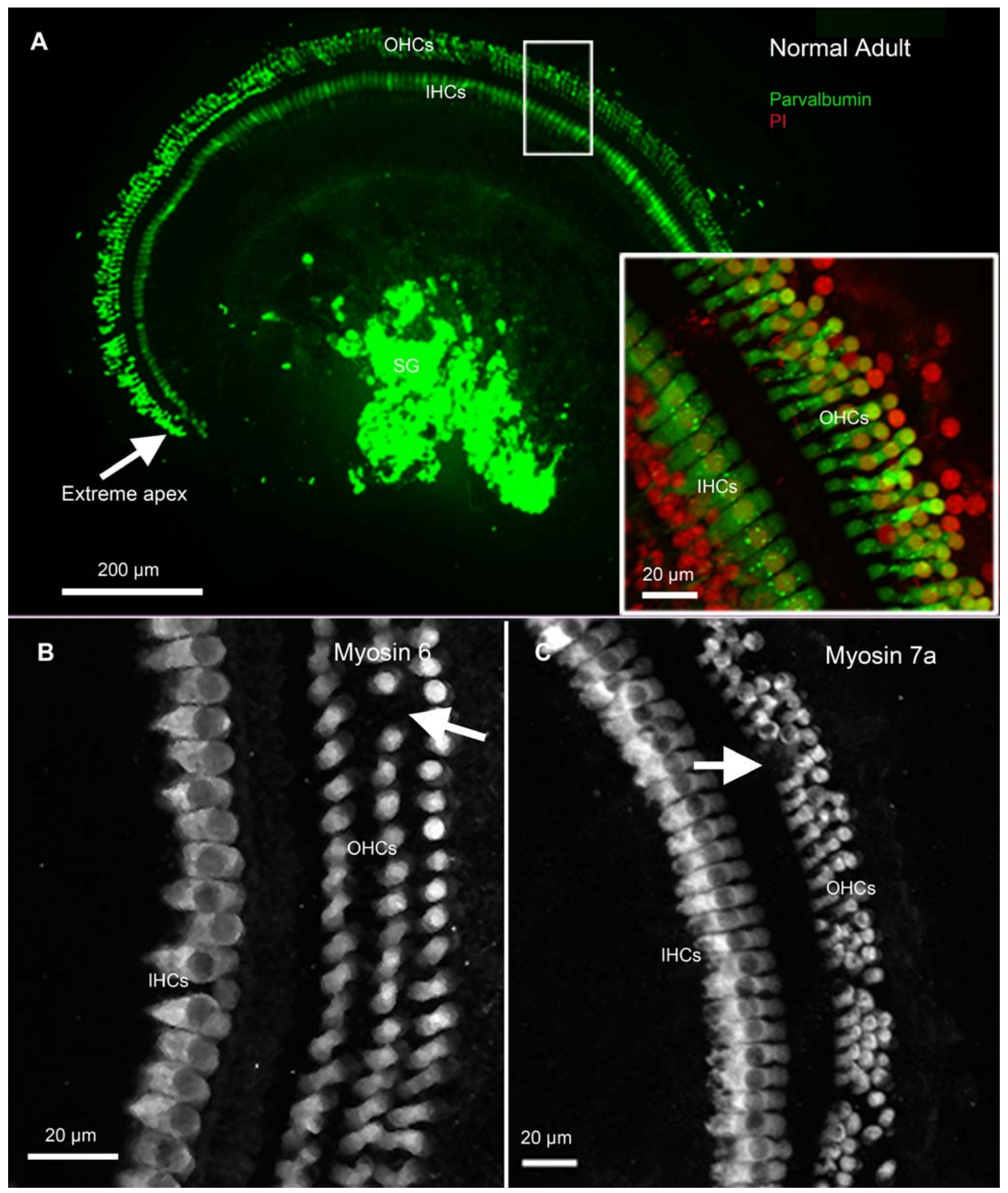

damaged regions validated the use of the HC markers to indicate $\mathrm{HC}$ loss at our recovery time points.

A total of 102 animals were treated with the kanamycin-furosemide injection set. Twelve percent of the injected animals (12 of 102) died, and increased deaths appeared to correlate to animals weighing above $35 \mathrm{~g}$. One lesion pattern was observed in roughly $80 \%$ of the animals that survived the injection set. This pattern will be described first, followed by descriptions of the less frequently ob- 
served lesion patterns. The most commonly observed lesion, where all three rows of OHCs throughout the length of the cochlea are killed by the drug treatment, is shown in Figure 2. In some of these animals, a few OHCs $(<100$ OHCs) are retained in the extreme apex (low-frequency region) of the cochlea. At 80 days recovery, the longest recovery time examined, the $\mathrm{OHC}$ region is replaced by SC scars, and no spontaneous recovery or regeneration of OHCs is apparent. OHCs, even apically located OHCs, appear more susceptible to the kanamycin-furosemide insult than IHCs. IHCs are generally present throughout the cochleas of these animals at all recovery times examined ( 1 to 80 days post-injections), but they may show signs of damage (Fig. 3B-D). Support cells in the organ do not appear to degenerate by 80 days post-injections, and the overall architecture of the organ of Corti remains remarkably normal. As shown in Figure 3, morphologically identifiable Deiters' and outer pillar cells persist in regions devoid of OHCs at 30 days of recovery. These cell types do not appear to

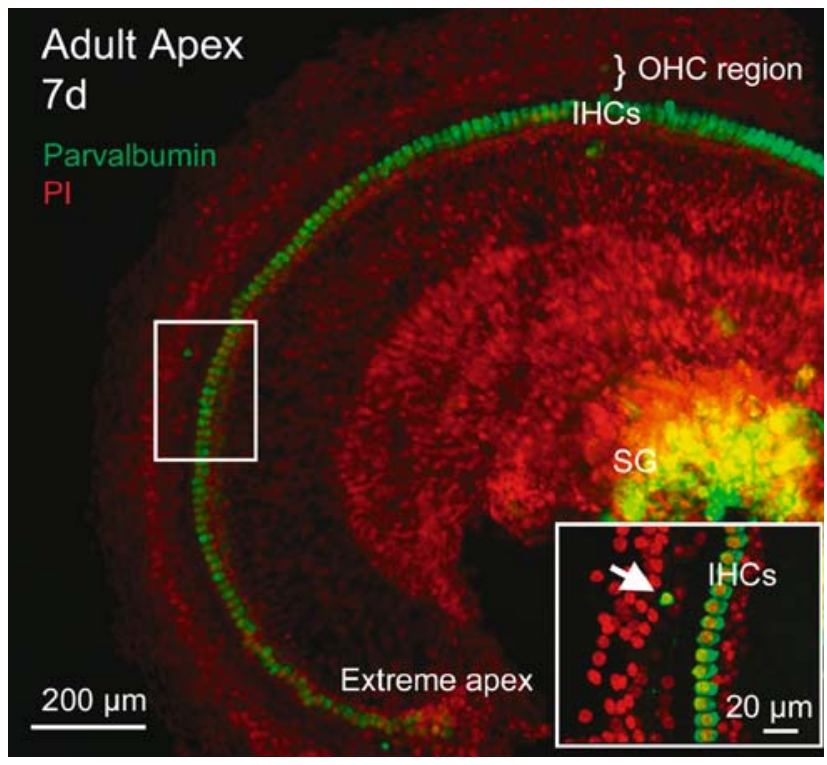

FIG. 2. OHCS are selectively killed by combined drug treatment throughout the cochlea. Shown are epifluorescent and confocal images of the apical turn of an adult mouse cochlea 7 days $(7 d)$ after systemic drug treatment with kanamycin and furosemide. The tissue was immunolabeled for the $\mathrm{HC}$-specific marker parvalbumin (green), and the nuclei were counterstained with propidium iodide $(\mathrm{Pl}, \mathrm{red})$. A whole-mount preparation of the turn is shown, and the boxed region is shown at a higher magnification in the inset. The bracket delineates the region normally occupied by outer hair cells $(\mathrm{OHCs})$. Virtually all OHCs have been killed, but inner hair cells (IHCS) remain throughout the turn. Inset brightest point projection from a confocal $Z$ series spanning through the more lumenal $\mathrm{HC}$ layer and more basal SC layer. The arrow points to a rare remaining $\mathrm{OHC}$. The nuclei of the support cells that remain in the $\mathrm{OHC}$ region are readily apparent. SG Spiral ganglion neurons. Scale bars $=20$ and $200 \mu \mathrm{m}$ for the inset and body of the figure, respectively.
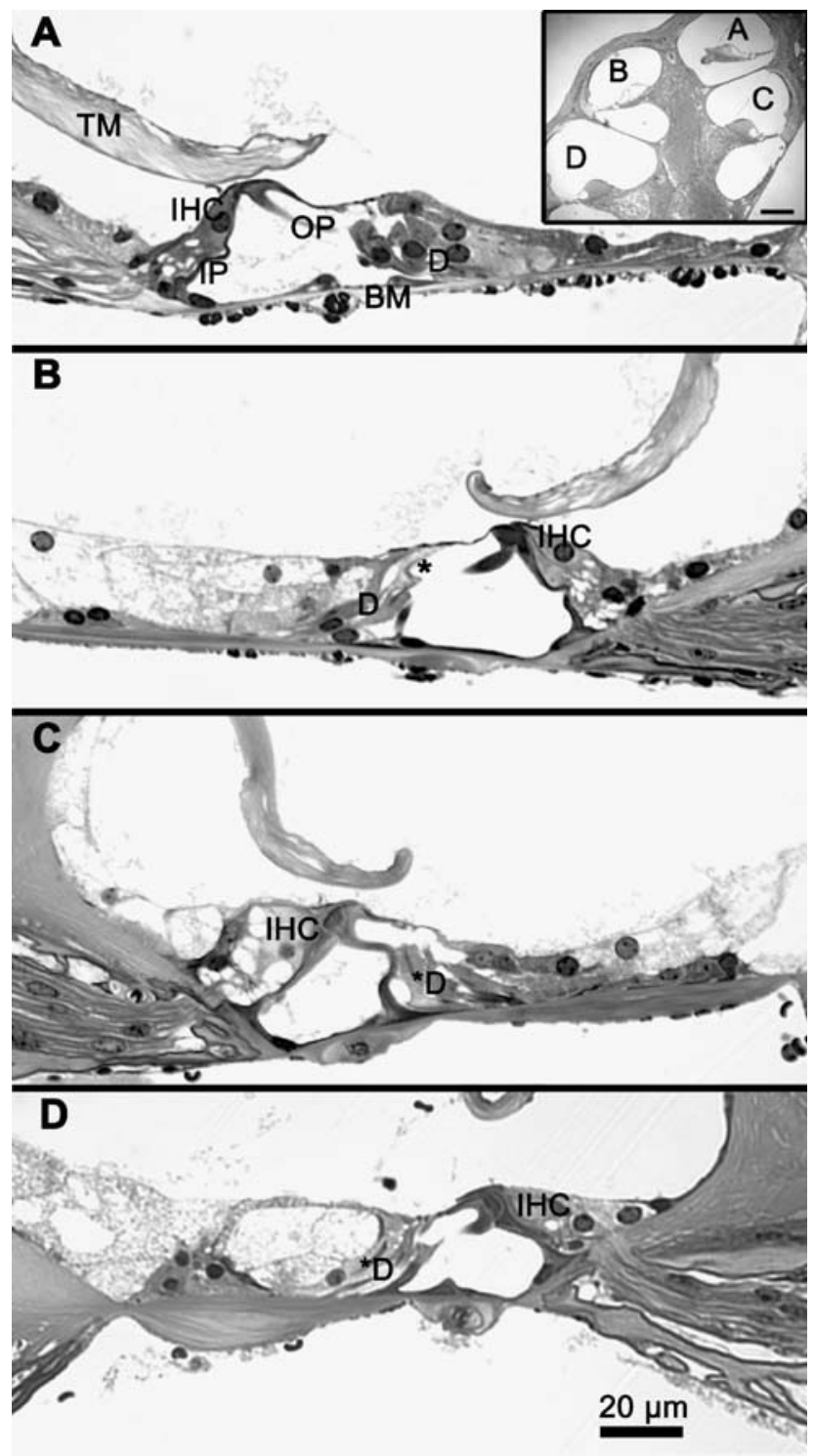

FIG. 3. Cross-sections of a cochlea from an animal killed 4 weeks after the kanamycin and furosemide injections. The photomicrographs are of a plastic-embedded cochlea taken from an adult mouse killed 4 weeks after kanamycin and furosemide treatment. OHCs, but not IHCs, are absent from all turns of the cochlea. The precipitate in the fluid spaces is thought to be a result of the decalcification step with RDO. Inset of (A) a cross-section through the cochlea. The turns are labeled, and the labels correspond to panels $(\mathbf{A}-\mathbf{D})$ where each turn is shown at a higher magnification. A Apical turn. OHCs are missing, but an inner hair cell $(I H C)$ remains. Deiters' cell $(D)$ nuclei can be seen. B Middle region. OHCs are missing from this region. Note the vacuolization within and below the IHC that is indicative of marked IHC and neural damage, respectively. Actin-microtubule filament bundles run within remaining Deiters' cells (e.g., asterisk). C-D Basal regions. OHCs are missing, and remaining IHCs are vacuolated. Filament bundles persist within the Deiters' and pillar cell cytoplasm (e.g., asterisks). BM Basilar membrane; IP inner pillar cell; $T M$ tectorial membrane. Scale bar in $\mathbf{D}=20 \mu \mathrm{m}$ and applies to panels (A-D). Scale bar in inset of $\mathbf{A}=200 \mu \mathrm{m}$. 
dedifferentiate markedly. Distinctive intracellular actin-microtubular filament bundles are prominent in pillar and Deiters' cell cytoplasm at 30 and 80 days of recovery (e.g., Fig. 3B-D).

In roughly $20 \%$ of the drug-treated animals, only patchy OHC loss is found (IHCs are present along the length of these cochleas). The patchy OHC lesion pattern is seen at both short and long recovery times (2-3 and 30 days post-injection). Some of the lesion variability, especially in animals with minor scattered OHC loss, may be the consequence of fluid leakage from the injection site or, more likely, the result of differences in absorption related to the delivery site. In a small number of animals, a significant number of IHCs were lost in addition to the OHCs (see below).

As a further measure of reproducibility and to address whether the lesion patterns are symmetric, the left and right ears of five drug-damaged animals were compared. Lesion patterns in the left ear strongly resemble those seen in the right ear, but on occasion (one of five animals), the IHC loss can be increased in one ear relative to the other (data not shown).

Although the majority of the experiments were conducted on outbred Swiss Webster mice, the kanamycin-furosemide injection set also induced similar lesions on inbred CBA mice. A few adult mice (Swiss Webster) were injected with either the kanamycin alone $(1,000 \mathrm{mg} / \mathrm{kg})$ or the furosemide alone (400 mg/kg) and allowed to survive for 3 , 7, or 14 days. HC loss was not observed in these animals beyond that seen in the non-injected, age-matched, and similarly processed controls.

\section{Time course of the $\mathrm{OHC}$ lesion}

The loss of OHCs is rapid, and the lesion continues to progress from base to apex several days after the

FIG. 4. The OHC loss occurs rapidly. Shown are photomicrographs of the apical turn of adult mice cochlea damaged by a single injection of kanamycin followed by a single injection of furosemide. The mice were killed 1 (A) or 2 (B) days after the injections to delineate the early timecourse of the lesion, and the tissues were immunolabeled for parvalbumin (green). A One day after the injections $(1 d)$, the outer hair cell $(\mathrm{OHC})$ loss is most pronounced in the basal-most portion of the apical turn, and the majority of the remaining $\mathrm{OHCs}$ are found in the region approaching the extreme apex. The area in the box is shown at a higher magnification at the bottom of the figure. B Apical turn from an animal that survived 2 days $(2 d)$ after the injections. The nuclei are counterlabeled with propidium iodide $(\mathrm{Pl}$, red). Nearly all of the OHCs are missing 2 days after the injections. The boxed region is shown at a higher magnification in the inset. The arrow points to a rare $\mathrm{OHC}$ that remains near the extreme apex. IHCS Inner hair cells; $S G$ spiral ganglion. Scale bars in (A) and $(\mathbf{B})=100 \mu \mathrm{m}$; scale bar in inset for panel $\mathbf{B}=20 \mu \mathrm{m}$. initial injections (Fig. 4). One day after drug treatment, more than $85 \%$ of the OHCs in the cochlea have been lost, including some occasional apical OHC loss. IHCs, in contrast, are intact (Fig. 4A). By 2 3 days after the injections, nearly all apical OHCs are missing. IHCs, in contrast, are present in near normal numbers (Fig. 4B). The lesion appears to be stabilized by 3 days post-injection, with large numbers of apical IHCs present at 1, 2, and 11 weeks of recovery (e.g., Figs. 2 and 3).
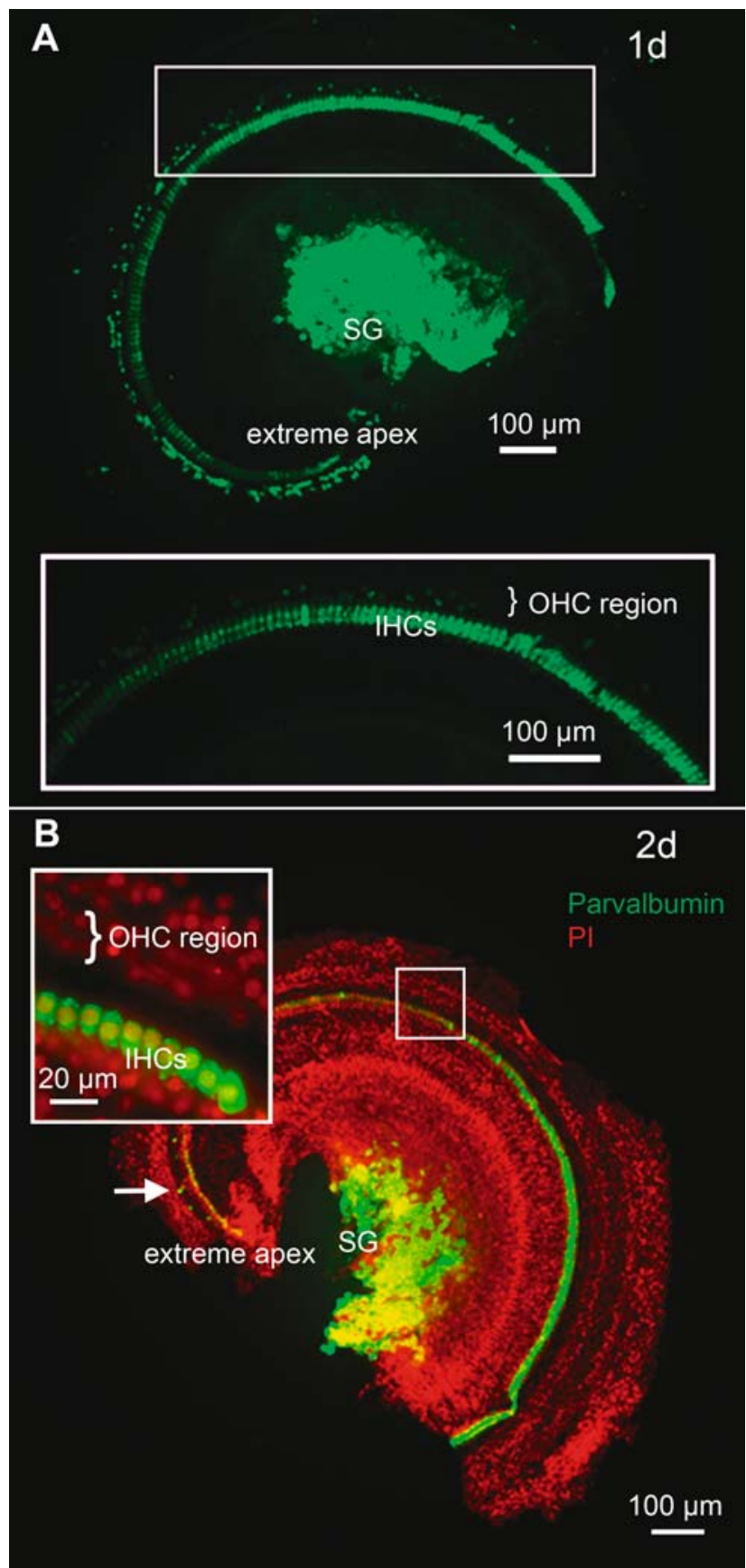


\section{IHCs and OHCs are lost in a subset of animals}

A small subset $(<5 \%)$ of lesioned animals demonstrate a significant loss of IHCs throughout the cochlea, in addition to the aforedescribed loss of OHCs. As illustrated in Figure 5, in these animals, IHCs (in addition to the complete OHC loss) can be missing from all turns of the cochlea, including the apical turn. There was no specimen in which the percentage of the IHC loss exceeded that of the OHC loss. Similar to the OHCs, there was no evidence for spontaneous recovery or regeneration of IHCs with 30- or 80-day recovery times.

To determine whether we could reliably increase the percentage of animals with significant apical IHC loss, we either: (1) increased the number of kanamycin-furosemide injection sets or (2) varied the age of the animal at the time of the injection. For the former, an injection set (single injection of $1,000 \mathrm{mg} / \mathrm{kg}$ kanamycin followed 30 to 45 min later by a single injection of $400 \mathrm{mg} / \mathrm{kg}$ furosemide) was administered each day for three or five sequential days to adult animals to determine whether the percentage of animals with significant IHC loss could be increased relative to that seen for animals with a single injection set. Animals with three $(n=4)$ or five $(n=3)$ sets of injections were allowed to survive for 10 or 14 days,

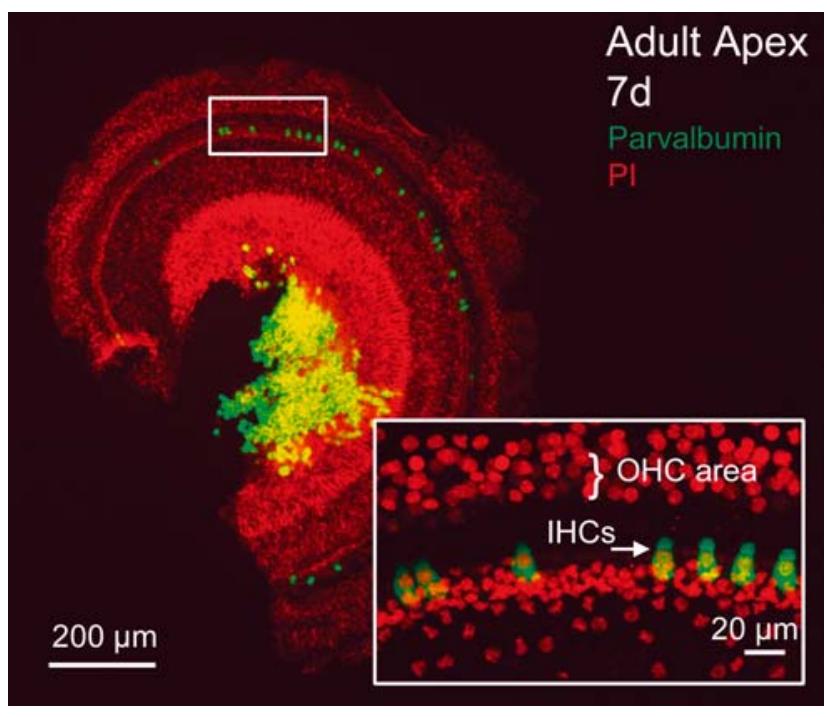

FIG. 5. OHCs and many IHCS are lost. Immunofluorescence for parvalbumin (green) labeling in the apical region of a cochlea taken from an animal injected once with kanamycin and once with furosemide and allowed to recovery for 7 days $(7 d)$. Nuclei were counterstained with propidium iodide $(P l, r e d)$. An epifluorescence image of the whole-mount preparation is shown along with a confocal image of the boxed area (inset). The confocal image is a brightest point projection of a $Z$ series stack spanning the full $\mathrm{HC}$ and much of the SC layers. OHCs are missing entirely from the apical turn, and scattered IHCs remain. Scale bar=200 and $20 \mu \mathrm{m}$ for the body of the figure and inset, respectively.
FIG. 6. Age and increased frequency of treatment does not increase IHC loss. The figures show whole-mount preparations of the apical turn of adult mice (A, B) or a P19 (C) animal. A Apical turn from an adult mouse injected with three sets of kanamycin and furosemide injections (one set per day for three sequential days) and killed 10 days later. The tissue is labeled for phalloidin, a marker for Factin, and the focus is at the level of the reticular lamina. Numerous X-shaped phalangeal SC scars are seen in all three rows of outer hair cells $(O H C s)$, suggesting the absence of the underlying OHCs. Inner hair cells (IHCS) are present out of the focal plane. B Apical turn from an adult mouse injected with five sets of kanamycin and furosemide injections (one set per day for five sequential days) and killed 14 days later. Hair cells are labeled with the HC-specific marker myosin 6 (green), and the nuclei are counterlabeled with propidium iodide $(\mathrm{Pl}$, red). A brightest point projection of a $Z$ series stack spanning through the $\mathrm{HC}$ layer is shown. IHCs remain, in contrast to the OHCs that are missing entirely from this region of the cochlea. $\mathbf{C}$ Apical turn from a P19 mouse injected with one set of kanamycin and furosemide injections and killed 14 days later. Hair cells are immunolabeled by parvalbumin (green) and nuclei are counterlabeled with PI (red). Many IHCs are present, but all three rows of OHCs are missing. SG Spiral ganglion. Scale bars in $\mathbf{A}$ and $\mathbf{B}=20 \mu \mathrm{m}$; Scale bar in $\mathbf{C}=100 \mu \mathrm{m}$.

and the apical turns of the cochleas were processed for parvalbumin or myosin 6 immunocytochemistry to identify HCs, or phalloidin labeling, and examined. OHCs are missing throughout the apical turns of these animals, but the majority of IHCs remain (Fig. 6A-B). The extent of the apical IHC loss in the animals with three or five sets of injections did not differ from that seen in animals with a single set of injections.

Young mice have been thought to be more sensitive to aminoglycosides than adults (Nakai et al. 1983; Chen and Saunders 1983; Prieve and Yanz 1984). Hence, for the second experimental paradigm, one set of injections (one kanamycin injection and one furosemide injection) was administered to P19 $(n=2)$ or P26 ( $n=4)$ animals. These animals survived for 7 or 14 days before tissue collection and immunofluorescence processing for parvalbumin or myosin 6 labeling. As in mature older animals, IHCs (but not OHCs) were present throughout the apical turns of the P19 and P26 animals (Fig. 6C), although occasional IHCs were missing. In summary, neither experimental paradigm markedly reduced the number of surviving IHCs relative to that seen in adult animals with a single set of kanamycin and furosemide injections.

\section{Absence of lesion in vestibular end organs}

Whole-mount preparations of utricles taken from kanamycin/furosemide-exposed animals were labeled with the HC-specific markers myosin 6 or $7 \mathrm{a}$ and examined to determine whether vestibular HCs were killed by the drug exposure. Utricles from nonexposed control animals were similarly processed and 


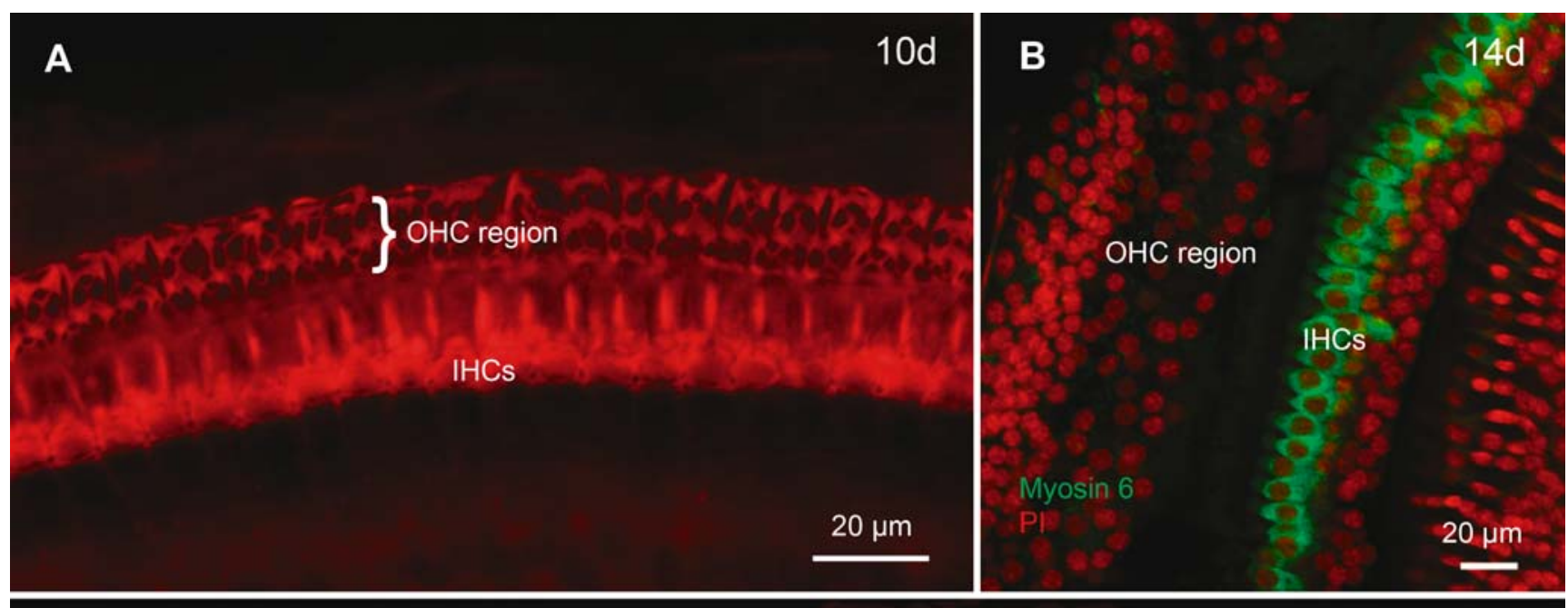

C

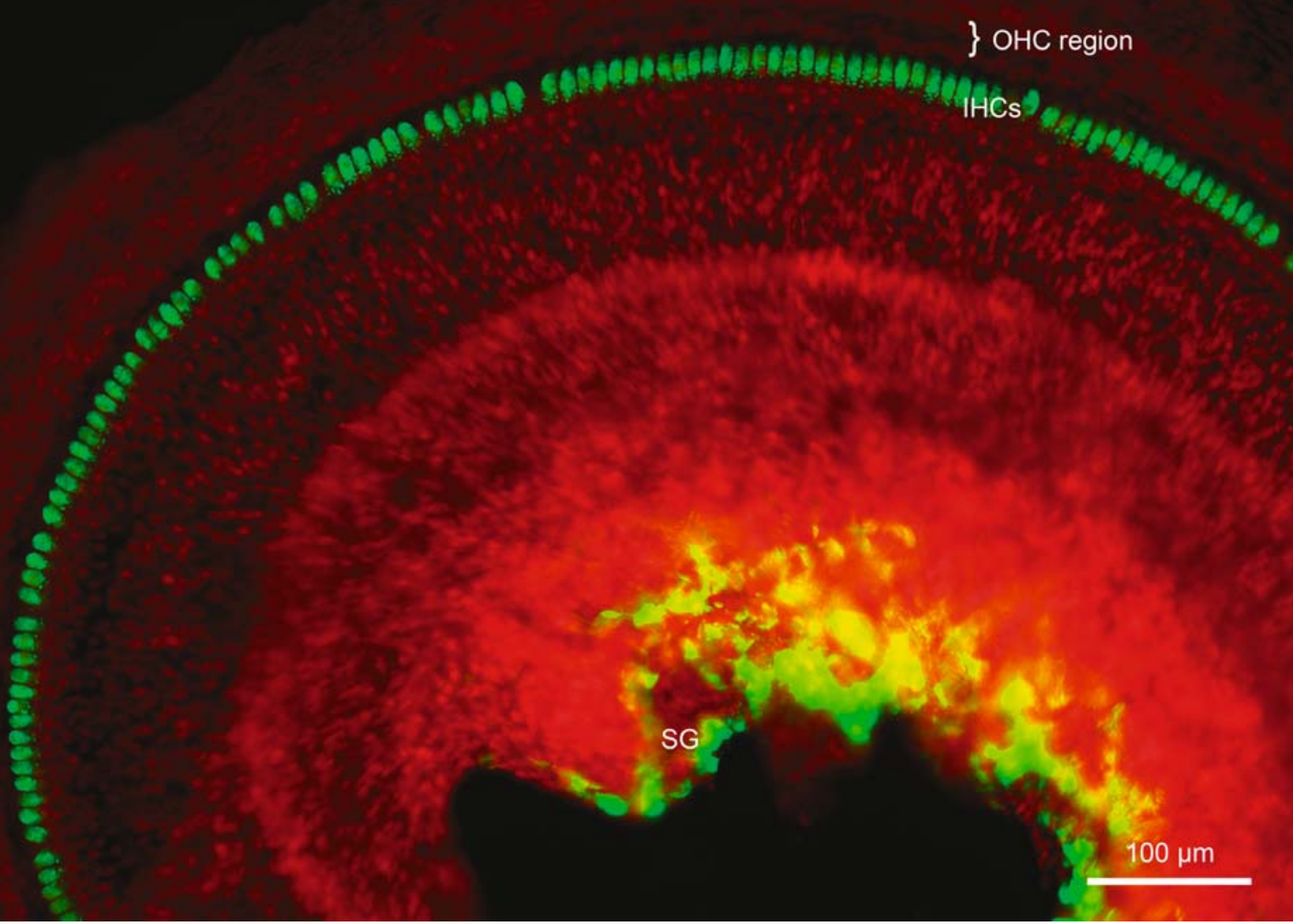

examined. A qualitative assessment of HC numbers in normal and drug-damaged animals did not reveal a marked loss of vestibular HCs in the drug-exposed animals, even within the striolar region. Vestibular HCs and SCs were intact in the drug-damaged animals. Abnormal behavior reflective of possible vestibular problems (e.g., circling, abnormal gate, head tilt) was not detected in the experimental mice.
Sox2 labels support cells in adult inner ear

We were interested in examining SC responsiveness to $\mathrm{HC}$ loss in the damaged adult mammalian inner ear and needed markers that would allow us to assay the SC response. We showed recently that the transcription factor Sox2 is expressed in developing mouse SCs (Hume et al. 2007). In other tissues, Sox2 is involved 

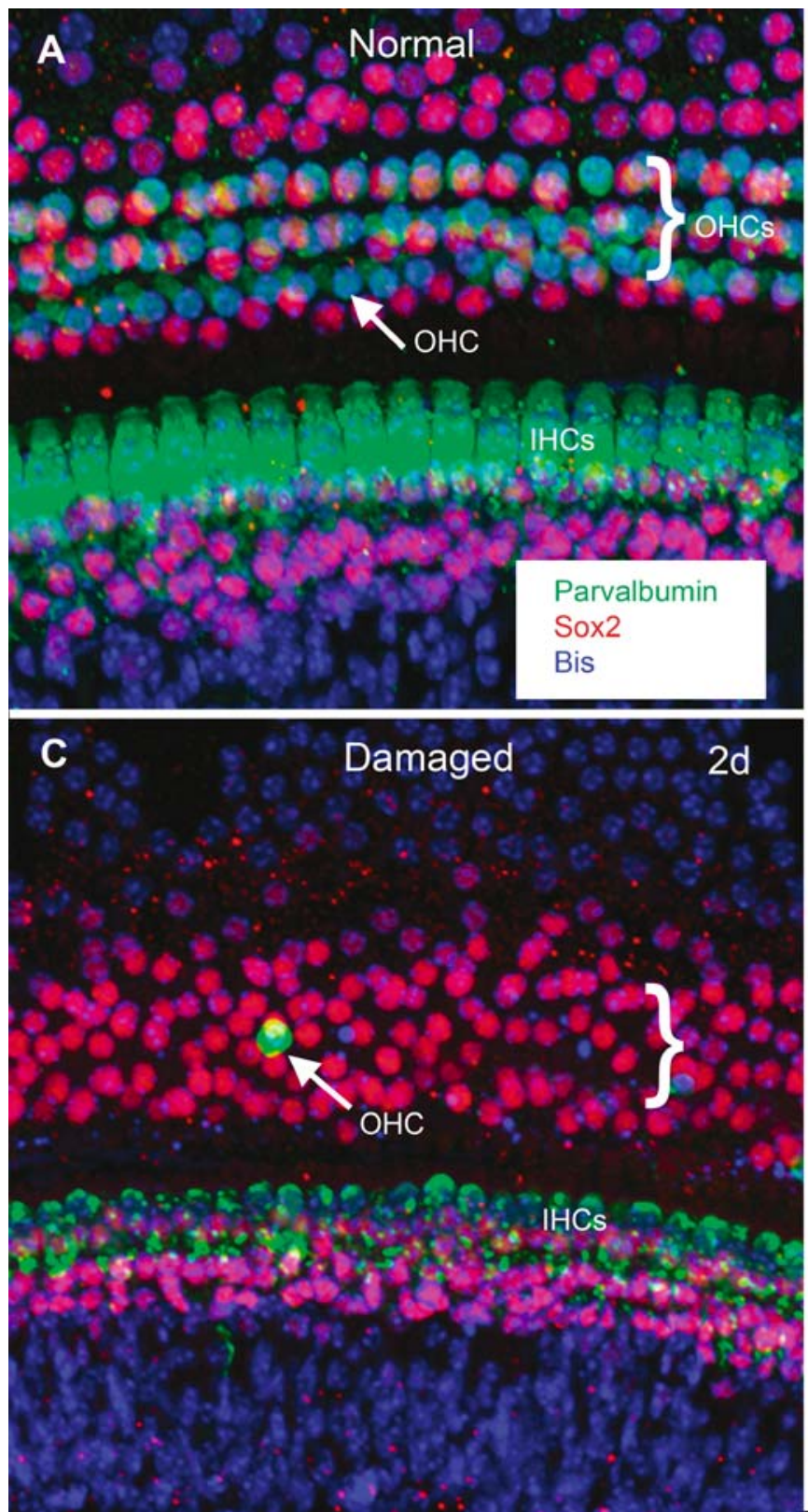

FIG. 7. Sox2 labeling in adult mouse cochlea. These confocal images were taken from whole-mount preparations of the apical turn of adult mouse organ of Corti that were immunolabeled for parvalbumin (green) and Sox2 (red). The nuclei were counterstained for bis (blue). The images are brightest point projections from $Z$ series stacks parallel to the reticular lamina (step size of $1 \mu \mathrm{m}$ ). A-B Apical turn from a normal undamaged organ of Corti. In part (A), all three channels are shown, whereas in (B), only the red channel with the Sox2 label is shown. Inner and outer hair cells are present, and they are labeled by parvalbumin which labels the HC cytoplasm. The transcription factor Sox2 is undetectable in $\mathrm{HC}$ nuclei. The arrow

in the proliferation of stem cells (Episkopou 2005; Wegner and Stolt 2005). In light of Sox2's being a distinguishing marker for stem and progenitor cells in many systems, recent evidence suggesting the presence of stem/progenitor cells in mature mammalian inner
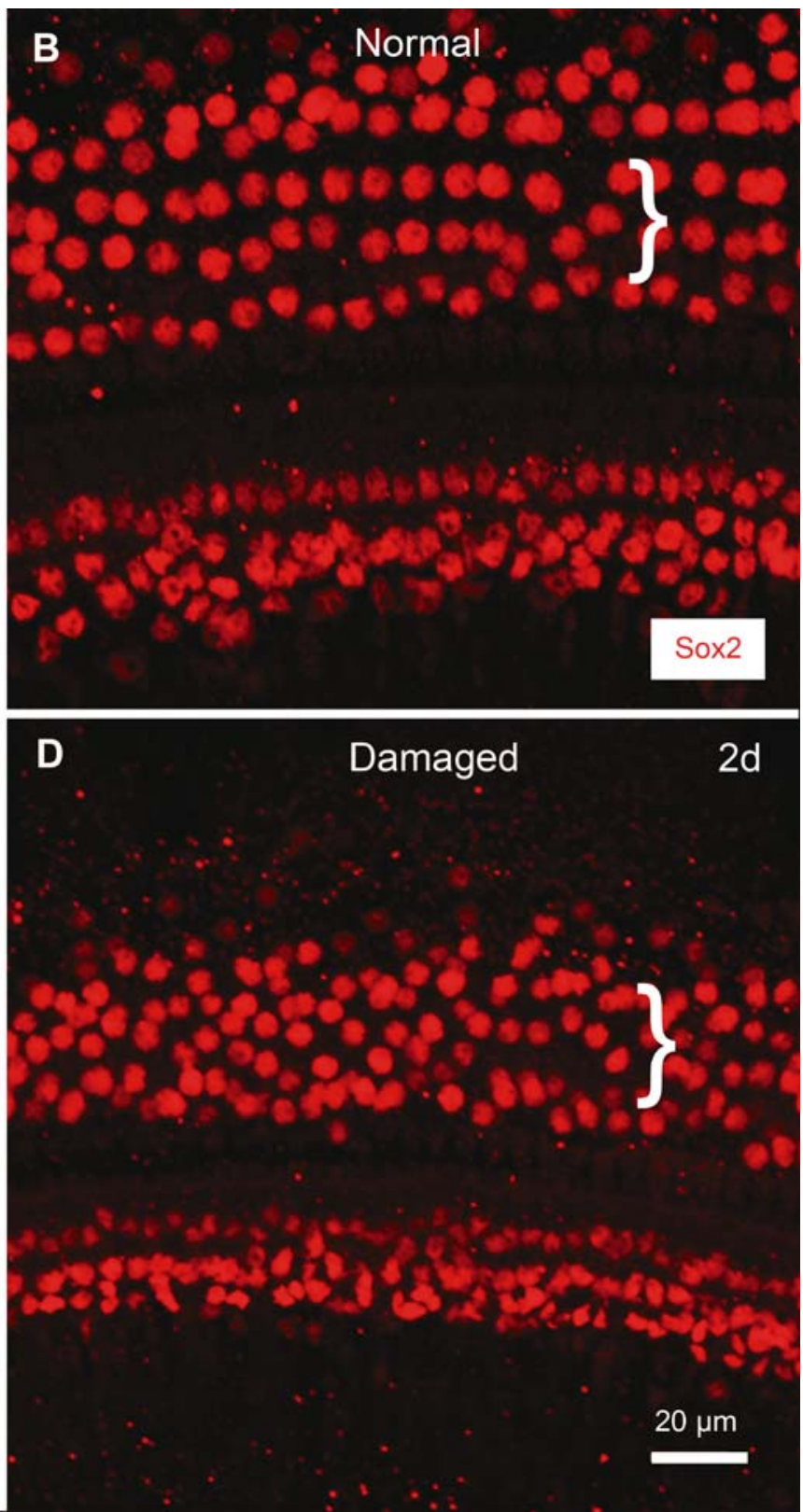

points to an individual $\mathrm{OHC}$, and the bracket delineates the $\mathrm{OHC}$ region. Sox2 labels the nuclei of all organ of Corti support cell types. C-D Apical turn from a drug-damaged mouse organ of Corti (one set of kanamycin and furosemide injections and 2 days of recovery). All three channels are shown in part (C), whereas only the red channel with the Sox2 label is shown in part (D). Inner hair cells are present in the tissue, and the arrow points to a rare remaining OHC. The bracket delineates the $\mathrm{OHC}$ region. Virtually all of the OHCs are missing. Sox 2 labeling is retained by all SCs in the damaged cochlea. Scale bar is identical for panels (A-D) and equals $20 \mu \mathrm{m}$.

ear ( $\mathrm{Li}$ et al. 2003a, b; Oshima et al. 2007), the need for SC-specific markers in the adult ear, and Sox2's expression in developing ear, we examined Sox2 expression in adult mouse inner ear. We used Sox2 to assay the $\mathrm{SC}$ response to drug-induced $\mathrm{HC}$ damage. 


\section{Normals}

Antibodies to the transcription factor Sox2 label the nuclei of all adult organ of Corti SC subtypes, namely, Hensen's, Deiters', inner and outer pillars, inner phalangeal, and border cells, in all turns of the normal adult mouse cochlea (e.g., Fig. 7A-B). In contrast, inner and outer HCs throughout the cochlea are unlabeled.

In the otolithic organs, the nuclei of the vestibular SCs are Sox2 positive throughout the macula, in striolar and extrastriolar regions (e.g., Fig. 8A). Rare Sox2-negative nuclei can be detected among the Sox2positive cells in the SC nuclear layer (arrows, Fig. 8A). A subset of nuclei in the HC-nuclear layer is Sox2 positive $(42.7 \pm 6.3 \% \mathrm{SD}, n=4$ organs). To characterize Sox2-positive nuclei in the $\mathrm{HC}$ layer, utricles were double labeled for Sox2 and the general HC-specific marker myosin 7a (Fig. 8B-C) or calbindin, a $\mathrm{Ca}^{2+}$ binding protein that delineates the striolar/juxtastriolar region by labeling calyx and dimorphic afferent terminals and neurons in the region (Dechesne and Thomasset 1988; Dechesne et al. 1988; Raymond et al. 1993; Leonard and Kevetter 2002; Fig. 8D-E). Both Sox2-positive (Sox2+/Myosin7a+) and Sox2-negative (Sox2-/Myosin7a+) HCs cells are seen throughout the macula (e.g., Fig. 8B). In the striolar/juxtastriolar region, which will herein simply be called the striolar region, Sox2-negative HCs are contacted by large calbindin-positive calyx endings (Fig. 8E). Both simple (one HC is innervated) and complex (more that one $\mathrm{HC}$ is innervated, arrow in Fig. $8 \mathrm{E}$ and inset) calbindin-positive calyx endings are seen with Sox2negative HCs, suggesting the Sox2-negative cells are Type I HCs. Sox2-positive HCs in the striolar region are not surrounded by calbindin-positive calyx endings, suggesting they are Type II HCs (e.g., arrowhead in Fig. 8E). A ratio of $1.1 \pm 0.2$ SD Sox2-negative to Sox2-positive HCs are seen in the striolar region (Table 1). Rare Sox2-/calbindin-negative nuclei are seen in the HC nuclear layer of the striolar region $\left(0.1 \pm 0.1 / 100 \mu \mathrm{m}^{2} \mathrm{SE}\right.$; Table 2$)$. In the extrastriolar region, Sox2-negative and Sox2-positive HCs are seen in a $1.5 \pm 0.3$ ratio (Table 1 ). The Sox2-positive HC nuclei tend to be located slightly higher (closer to lumen) in the epithelium than nuclei of Sox2-negative HCs. A few Sox2+ cells are seen within the stromal region of the otolithic organs (data not shown).

The posthatch chicken ear, in contrast to the mammalian inner ear, generates new HCs to replace those lost to insult (reviewed in Oesterle and Stone 2008). Sox2 expression patterns were also examined in normal posthatch (P7-P10) chicken inner ear. Despite marked differences in the regenerative repair capacities of mammalian and chicken auditory end organs, Sox2 expression is remarkably similar in the two animal species. Like the mouse, Sox2 specifically labels SCs, but not HCs, throughout the chicken auditory sensory epithelium, the basilar papilla (Fig. 9). In the utricular macula, vestibular SCs are Sox2-positive, and a subset of vestibular HCs expresses Sox2 (data not shown).

\section{Drug-damaged}

In animals treated with kanamycin and furosemide, Sox2 expression is maintained in the SCs throughout the damaged cochlea at all recovery times examined (2 days, 7, 365 days). As shown in Figure 7C-D, Sox2 expression is maintained in all subtypes of SCs in the organ of Corti: Hensen's, Deiters', pillar, inner phalangeal, and border cells.

Sox2 is expressed by vestibular SCs in utricles taken from the drug-damaged animals (data not shown). A qualitative assessment of $\mathrm{HC}$ numbers in normal versus drug-damaged animals did not reveal a marked loss of vestibular HCs in the drug-exposed animals, even within the striolar region.

Jagged1 labels support cells in adult inner ear

\section{Normals}

Jagged1 is expressed in embryonic SCs in mouse organ of Corti, but its expression in the adult ear is unknown (Zine and de Ribaupierre 2002; Woods et al. 2004; Brooker et al. 2006; Jones et al. 2006; Murata et al. 2006). Because of its presence in developing SCs, we examined its expression in normal and drugdamaged adult ears. Neonatal (P1) organ of Corti served as the positive control tissue for these studies. As shown in Figure $10 \mathrm{~A}-\mathrm{B}$, Jagged1 is specifically expressed in SC membranes in organ of Corti taken from P1 mice. Jagged1 labeling is also seen in the membranes of the cells of the greater epithelial ridge, cells that undergo cellular rearrangements that eventually give rise to the inner sulcus region similar to that as described in Lim and Rueda (1992). In the adult organ of Corti, Jagged1 immunolabeling is seen in all organ of Corti SC subtypes (Hensen's, Deiters', pillar, inner phalangeal, and border cells; Fig. 11A, C). Jagged1 is expressed at lower levels outside of the organ of Corti, in inner and outer sulcus cells (Fig. 11A).

Jagged1 immunoreactivity is present in SC membranes in the P1 vestibular epithelium and, at lower levels, in membranes of the neighboring transitional epithelial cells (data not shown). In adults, Jagged1 expression persists in SC membranes throughout the macula of the otolithic organs, as well as in the transitional epithelial cells (Fig. 12). Jagged1 expression is undetectable in neonatal and adult vestibular HCs (Fig. 11C). 

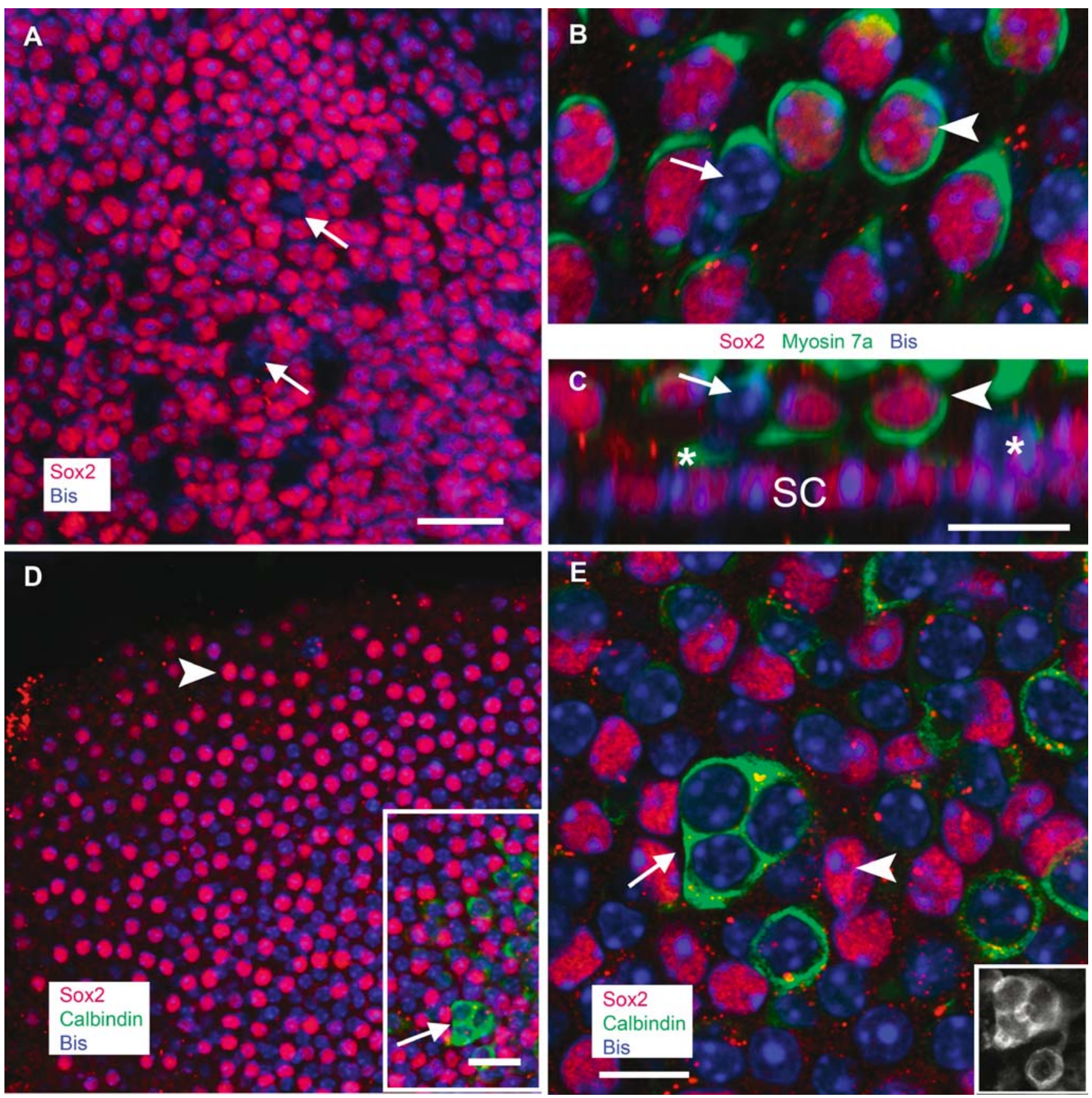

\section{Drug-damaged}

Jagged 1 expression was examined in the drug-damaged organ of Corti at 1, 2, 3, and 7 days of recovery. Labeling in the drug-damaged organ is maintained and resembles that seen in the normal ear. Labeling of organ of Corti SCs is seen with the C-20 antibody at all recovery times examined (e.g., Fig. 11B, D). Jagged1 expression was not examined in detail in the vestibular organs of the drug-injected animals, because the kanamycinfurosemide protocol did not induce marked vestibular lesions.

\section{DISCUSSION}

Progress toward HC regeneration in mammals has been frustratingly slow partially because of the inadequacy of available animal models of ototoxicity and a lack of SC markers to assist in the analysis of regenerative processes. We developed a reliable systemic protocol to eliminate HCs in vivo in the organ of Corti of adult mice. Using this damage protocol, OHCs throughout the adult mouse cochlea are killed rapidly by a single injection of kanamycin $(1,000 \mathrm{mg} / \mathrm{kg})$ followed by a single injection of the 
FIG. 8. Confocal images of Sox2 expression in adult mouse vestibular sensory epithelia. The images in parts $\mathbf{A}-\mathbf{E}$ are brightest point projections from levels of $Z$ series stacks taken parallel to the reticular lamina (step size $=1 \mu \mathrm{m}$ ). The images are from whole-mount preparations of normal adult mouse utricles immunolabeled for Sox2 (red; A-E) and the HC-specific marker myosin 7a (green; B-C), or the calcium-binding protein calbindin (green; D-E), which delineates the striolar region. The nuclei are counterstained for bisbenzimide (b/ue). The mammalian vestibular sensory epithelium contains SCs, nerve fibers, terminals, and two types of HCs. Type I HCs are flask shaped and enclosed in a nerve calyx, whereas Type II HCs are cylindrical and have multiple bouton-type nerve endings. The HCs are distributed along the luminal surface of the epithelium, and their cell bodies do not make contact with the basal lamina. Support cells are interposed between HCs, and their cell bodies typically extend the entire depth of the epithelium, from the lumen to the basal lamina. Support cell nuclei reside primarily within the basal half of the epithelium, whereas $\mathrm{HC}$ nuclei reside in the luminal half. A SC nuclear layer. The image is the brightest point projection, where nuclei in the SC layer are in focus. Sox2 (red) labels SC nuclei. A rare unlabeled nucleus can be observed (e.g., arrows). Gaps occur in the nuclear layer where nerve fibers penetrate the layer. $\mathbf{B}$ HC layer. The image is a $Z$ series projection where Sox2-positive HC nuclei are in focus. Double labeling with Sox2 (red) and myosin 7a (green) shows that a subset of vestibular HCs is Sox2 positive (e.g., arrowhead). Sox2-negative HCs are also present (e.g., arrow) in this $Z$ plane, but they predominate in planes located slightly lower in the epithelium as shown in part $\mathbf{C}$, a $Z$ plane cross-section of the region shown in (B). C Two Sox2-negative HCs (asterisks) are located lower in the epithelium than the Sox2-positive HCs. Myosin labeling for the rightmost Sox2-negative $\mathrm{HC}$ is not readily apparent in this section but becomes prominent in subsequent $Z$ plane cross-sections (data not shown). A portion of the nucleus of the leftmost Sox2-negative $\mathrm{HC}$ is visible, and the nucleus comes into focus in adjacent $Z$ plane cross-sections. SC supporting cell nuclear layer. D Extrastriolar and striolar HCs. Sox2-positive and Sox2-negative HCs are present in the extrastriolar region (left part of image). The boxed region, shown at a higher magnification in part $\mathbf{E}$, delineates a small region of striolar tissue. E Striolar HCs. Calbindin (green) labels large afferent nerve fibers that surround Type I HCs that are Sox2-negative (e.g., arrow). The calyx indicated by the arrow is shown in the inset, where only the green channel with the calbindin labeling is shown. One branch of the nerve fiber contacts three HCs and the second branch contacts another HC. Both Sox2-positive (arrowhead) and Sox2-negative HCs (e.g., arrow) are present in the striolar region. Scale bars $=20 \mu \mathrm{m}$ in panels $\mathbf{A}$ and $\mathbf{D}$ and $10 \mu \mathrm{m}$ in panels $(\mathbf{B}-\mathbf{C})$ and $(\mathbf{E})$.

loop diuretic furosemide $(400 \mathrm{mg} / \mathrm{kg})$. We also describe the use of two new markers of adult SCs, Sox2 and Jagged1, to characterize the normal and drug-damaged inner ear. The transcription factor Sox2 is expressed by organ of Corti and vestibular SCs in adult mouse and posthatch chicken inner ear. A subset of HCs in the vestibular, but not auditory, SE of the adult mouse and posthatch chicken ear also expresses Sox2. Jagged1, a ligand member of the Notch signaling pathway, is expressed in vestibular and auditory SCs in adult mouse inner ear. Jagged1 and Sox2 expression in inner ear SCs in the adult are not affected by drug damage.

\section{Advantages and disadvantages of mouse model}

Studies of drug-induced hearing loss have been hampered by the lack of a good mouse model.
TABLE 1

Quantification of Sox2-negative (Sox2-) and Sox2-positive (Sox2+) nuclei in the HC layer in normal adult mouse utricle

\begin{tabular}{|c|c|c|}
\hline & Striola/Juxtastriola & Extrastriola \\
\hline \multicolumn{3}{|l|}{ Density per $100 \mu \mathrm{m}^{2} \mathrm{SE}$} \\
\hline Sox2- nuclei/100 $\mu \mathrm{m}^{2}$ & $0.7 \pm 0.2$ & $1.0 \pm 0.2$ \\
\hline Sox $2+$ nuclei $/ 100 \mu \mathrm{m}^{2}$ & $0.7 \pm 0.1$ & $0.7 \pm 0.1$ \\
\hline $\begin{array}{l}\text { Total nuclei }(\text { Sox } 2 \pm) / \\
100 \mu \mathrm{m}^{2}\end{array}$ & $1.4 \pm 0.3$ & $1.7 \pm 0.4$ \\
\hline \multicolumn{3}{|l|}{ Percentage of total } \\
\hline$\%$ Sox $2-$ nuclei & $50.9 \pm 6.1$ & $59.6 \pm 4.5$ \\
\hline$\%$ Sox $2+$ nuclei & $49.1 \pm 6.1$ & $40.4 \pm 4.5$ \\
\hline \multicolumn{3}{|l|}{ Ratio } \\
\hline $\begin{array}{l}\text { Sox } 2-/ \text { Sox } 2+\text { ratio } \\
\text { (presumed Type I/Type II } \\
\text { HC ratio) }\end{array}$ & $1.1 \pm 0.2$ & $1.5 \pm 0.3$ \\
\hline
\end{tabular}

Values are means $\pm \mathrm{SD}$

$N=2-4$ organs; four to five areas sampled per region per organ

All nuclei were counterstained with bisbenzimide.

Experimental protocols to induce $\mathrm{HC}$ damage in mice with ototoxic drugs have been limited by systemic toxicity, the need for repeated applications to produce damage, lesion variability, lack of rapid HC damage after a single application, and/or the necessity of surgery for the drug administration. In this report, we describe a nonsurgical approach for inducing $\mathrm{HC}$ damage in vivo in adult mouse organ of Corti by a single high-dose injection of aminoglycoside,

TABLE 2

Quantification of calbindin and Sox2 double labeling in the $\mathrm{HC}$ layer in normal adult mouse utricle

\begin{tabular}{lcc}
\hline & Striola/juxtastriola & Extrastriola \\
\hline $\begin{array}{l}\text { Density per } 100 \mu \mathrm{m}^{2} \mathrm{SE} \\
\text { Calbindin+Sox-/ } \\
100 \mu \mathrm{m}^{2}\end{array}$ & $0.7 \pm 0.2$ & $0 \pm 0$ \\
$\begin{array}{l}\text { Calbindin+Sox+/ } \\
100 \mu \mathrm{m}^{2}\end{array}$ & $0 \pm 0$ & $0 \pm 0$ \\
$\begin{array}{l}\text { Calbindin-Sox-/ } \\
100 \mu \mathrm{m}^{2}\end{array}$ & $0.1 \pm 0.1$ & $1.0 \pm 0.2$ \\
$\begin{array}{l}\text { Calbindin-Sox+/ } \\
100 \mu \mathrm{m}^{2}\end{array}$ & $0.7 \pm 0.1$ & $0.7 \pm 0.7$ \\
$\begin{array}{l}\text { Percentage of total } \\
\% \text { Calbindin+ Sox2- }\end{array}$ & $37.9 \pm 5.9$ & \\
$\%$ Calbindin+ Sox2+ & $0 \pm 0$ & $0 \pm 0$ \\
$\%$ Calbindin- Sox2- & $13.2 \pm 6.6$ & $0 \pm 0$ \\
$\%$ Calbindin- Sox2+ & $49.1 \pm 6.1$ & $40.4 \pm 4.5$ \\
\hline
\end{tabular}

Total $=$ striola/juxtastriola and extrastriola regions combined

Values are means \pm SD.

$\mathrm{N}=2-4$ organs; $4-5$ areas sampled per region per organ

All nuclei were counterstained with bisbenzimide. Calbindin-labeled nerve fibers surround a subset of HCs in the striolar/juxtastriolar region only.

Calbindin+/Sox+ denotes a Sox2-positive nucleus in the $\mathrm{HC}$ layer that is surrounded by a calbindin-positive nerve fiber, Calbindin $+/$ Sox - denotes a bisbenzimide (Sox2-negative) labeled nucleus in the HC layer surrounded by a calbindin-positive nerve fiber. 

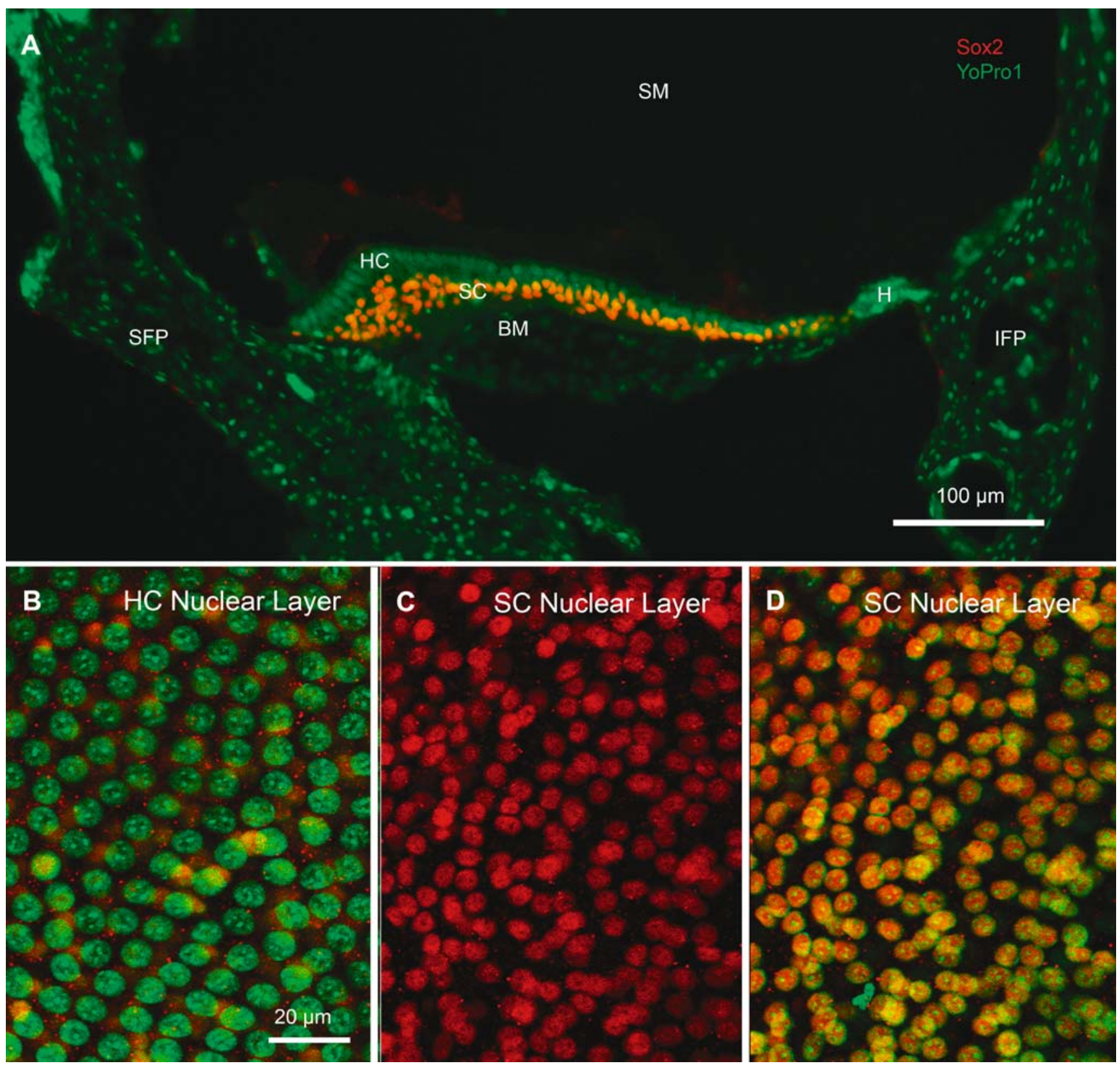

FIG. 9. Sox2 expression in normal posthatch chicken basilar papilla. Immunofluorescent labeling for Sox2 (red) in cryosections (A) and whole-mount preparations (B-D) of auditory sensory epithelium (basilar papilla) taken from normal posthatch chickens. Nuclei are counterlabeled with YoPro1 (green) (A) or DAPI and pseudo-colored green (B, D). A Cross-section of the cochlear duct. Sox2 expression is specific to support cells $(S C)$ in the basilar papilla. Cells in adjacent extrasensory tissues are unlabeled. Sox2 expression is not detected in auditory hair cells $(H C)$. B-D The images in parts B-D are brightest point projections from a confocal $Z$ series stack taken from a whole-mount preparation of normal chicken basilar

kanamycin, followed by a single injection of a loop diuretic, furosemide. This protocol results in a rapid and consistent loss of the OHCs along virtually the entire length of the cochlea. The rapidity of this technique will facilitate new studies of early events papilla immunolabeled for Sox2 (red). DAPI-labeled nuclei are pseudo-colored green. Levels spanning the $\mathrm{HC}$ and SC nuclear layers are shown in panels $(\mathbf{B})$ and $(\mathbf{C}-\mathbf{D})$, respectively. Auditory HCs are not labeled by Sox2 (B). C-D SC nuclear layer. The red channel with the Sox2 labeling is shown in $(\mathbf{C})$, and both the red and green channels are shown in (D). Sox2 is expressed in virtually all of the support cells. SM Scala media; SFP superior fibrocartilaginous plate; IFP inferior fibrocartilaginous plate; $H$ hyaline cells; $B M$ basilar membrane. The scale bar in (A) equals $100 \mu \mathrm{m}$. The scale bar in (B) equals $20 \mu \mathrm{m}$ and applies to panels (B-D).

after drug damage. The processes of HC death, survival, and repair/regeneration can also be further examined and manipulated in genetically modified animals with the goal of improving our understanding of the underlying molecular mechanisms. 

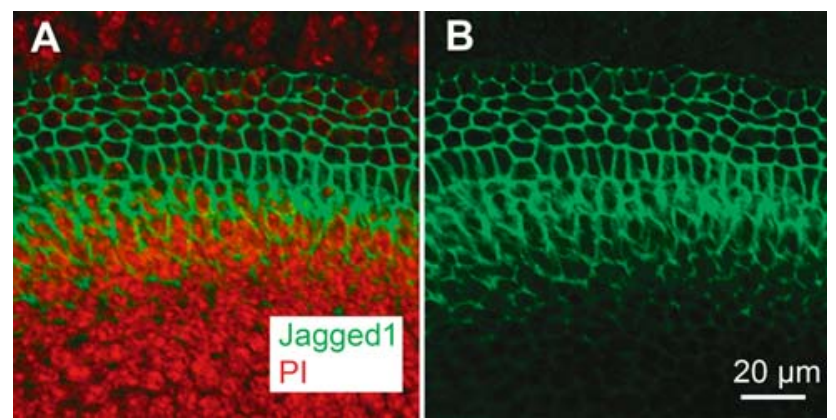

FIG. 10. Jagged1 expression in P1 organ of Corti. A Confocal optical section of the apical region of a normal P1 mouse cochlea in a plane passing through the bodies of the SCs at a deeper level than the HCs. The membranes of the SCs are immunolabeled with the Jagged1 antibody (green). Nuclei are counterlabeled with PI (red). B Only the green channel with the Jagged1 labeling is shown. Scale bar $=20 \mu \mathrm{m}$ and applies to both panels.

\section{Mechanisms underlying furosemide and kanamycin ototoxic effect}

Aminoglycoside antibiotics, discovered in the 1940s, have long been known to have substantial ototoxic and nephrotoxic effects in clinical use (reviewed in Humes 1999; Schacht and Hawkins 2006). Furosemide, bumetanide, and other loop diuretics are ototoxic clinically, but the hearing loss is mostly reversible. Systemic or intracochlear administration of furosemide induces rapid reversible changes in a number of stimulus-related responses, including receptor potentials (Forge and Brown 1982), auditory nerve responses (Evans and Klinke 1982), and basilar membrane vibration (Ruggero and Rich 1991). Two structures have been considered as primary sites of furosemide action in the cochlea: the stria vascularis and the HCs. The predominant ototoxic effects of furosemide on cochlear function are believed to result from its interference with stria vascularis function (Brown and McElwee 1972; Kusakari et al. 1978a; Wangemann 1995). Furosemide, and other loop diuretics such as bumetanide, causes an acute enlargement of the intrastrial space (Santi and Duvall 1979; Pike and Bosher 1980; Santi and Lakhani 1983) in association with a decline in the positive endocochlear potential (EP; Kusakari et al. 1978a, b). Bumetanide inhibits the $\mathrm{Na}^{+}-\mathrm{K}^{+} 2 \mathrm{Cl}^{-}$cotransporter, which is abundantly expressed in the basolateral membrane of the marginal cells (Crouch et al. 1997; Mizuta et al. 1997). Whereas the predominant ototoxic effects of loop diuretics on cochlear function are thought to result from their interference with stria vascularis function, the loop diuretics also appear to interact directly with HCs and directly alter the motility of OHCs (Santos-Sacchi et al. 2001).

Furosemide and other loop diuretics are wellknown potentiators of aminoglycoside effects. The combined administration of a loop diuretic with an aminoglycoside — each at a nontoxic dosage — - leads to a rapid and profound hearing loss in humans and animals (Mathog and Klein 1969; Meriwether et al. 1971; Brummett et al. 1975, 1981; Santi et al. 1982). The mechanisms underlying the synergistic effects of aminoglycosides and loop diuretics on HC ototoxicity remain to be fully elucidated. Tran Ba Huy et al. (1983) proposed that the ototoxic potentiation by loop diuretics is caused by the facilitation of penetration of aminoglycosides into the endolymph. A loop diuretic-induced reduction of the normally positive EP to negative values could facilitate entry of the positively charged aminoglycosides into the endolymph (Taylor et al. 2007). Aminoglycosides in the endolymph are then thought to enter the HCs largely through the mechano-transducer channels that effectively act as a one-way value for the passage of the aminoglycoside. They become trapped in the HCs so that they accumulate and cause their ototoxic effects (Farris et al. 2004; Marcotti et al. 2005). Marcotti et al. (2005) propose that aminoglycoside entry through the transducer channel would lead to a direct relation between resting transducer current size and drug entry and that this might explain why OHCs, which have larger transduction currents, are more susceptible than IHCs (Kros et al. 1992; He et al. 2004). Results in an accompanying paper, however, suggest an equivalent aminoglycoside uptake in IHCs and OHCs (Taylor et al. 2007). Hence, the increased resistance of IHCs to aminoglycoside-induced damage would not be explained by a differential uptake of the drug.

\section{Support cell degeneration after HC loss}

In some models, extensive HC death in the adult rodent organ of Corti can lead to SC death and complete degeneration of the organ within weeks (Bichler et al. 1983; Fredelius 1988; Fredelius et al. 1988; Lenoir et al. 1999). The underlying causes for the SC death are unknown. Conceivably, they could be a consequence of a loss of trophic factors normally supplied to SCs by HCs or nerve fibers innervating the HCs leading to the secondary degeneration of the SCs. Immunohistochemical studies suggest SCs may take up aminoglycosides (De Groot et al. 1990; Imamura and Adams 2003), but studies examining uptake of radioactively labeled aminoglycoside in organ of Corti cells demonstrate little uptake in SCs. Hence, it appears unlikely that the SC death is the result of a direct aminoglycoside-induced toxicity to the SCs themselves (Aran et al. 1995; Richardson et al. 1997, 1999). With our kanamycin-furosemide lesion paradigm, where OHCs are preferentially lost throughout the cochlea, we observed that SCs do not appear to degenerate markedly by 1 to 3 months 


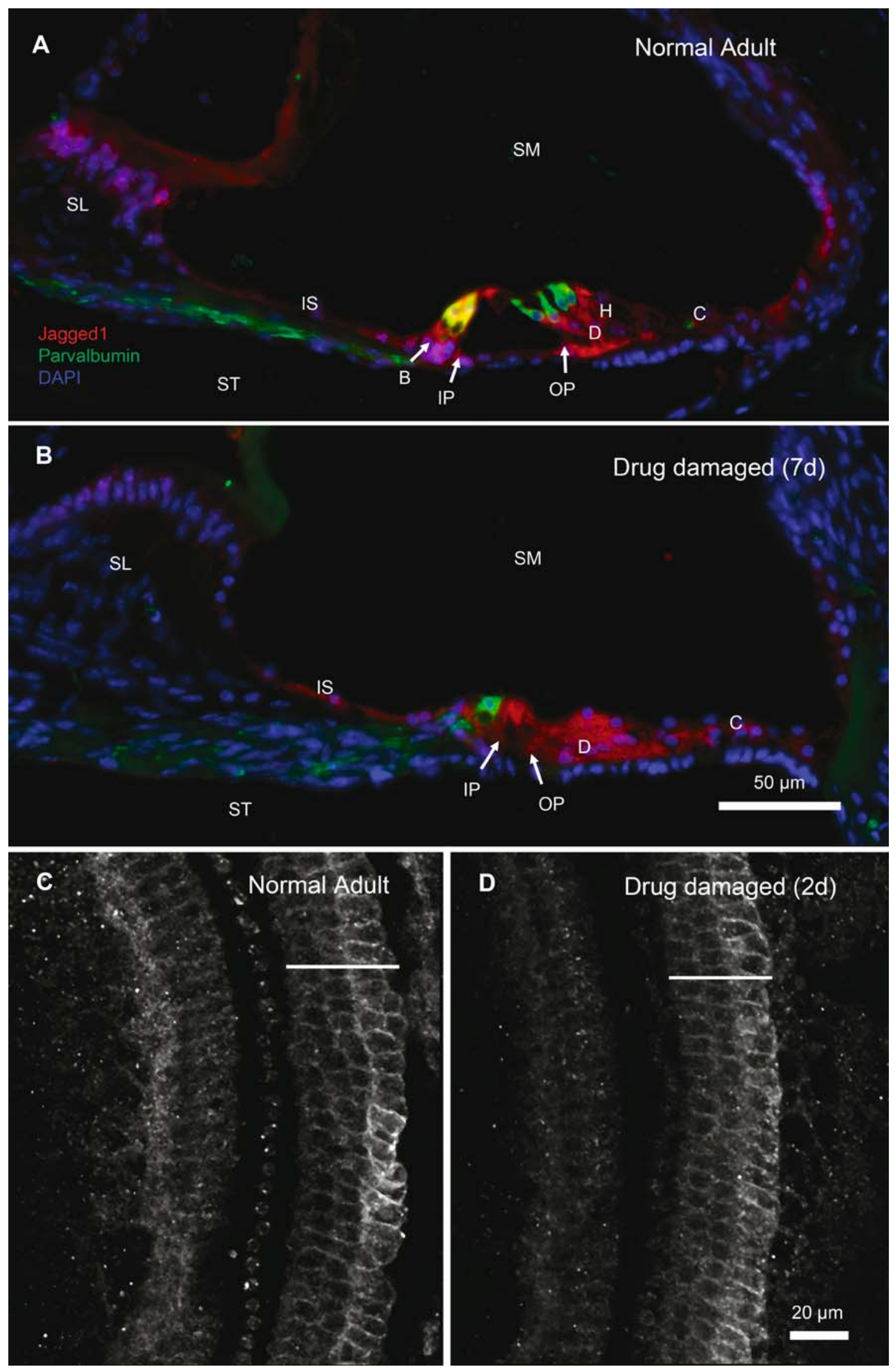


FIG. 11. Jagged1 expression in adult organ of Corti. Cryostat sections of normal (A) and kanamycin-furosemide damaged (B) adult organ of Corti (apex) immunolabeled with Jagged1 (red, C-20 antibody) and parvalbumin (green). Nuclei are counterlabeled with DAPI (blue). The drug-damaged animal (B) was killed 7 days $(7 d)$ after the drug injections. Jagged1 labels SCs in normal and drugdamaged adult organ of Corti. To illustrate the membrane-specific nature of the Jagged1 labeling, whole-mount preparations of normal and kanamycin-furosemide damaged adult organ of Corti (apex) immunolabeled with Jagged1 (C-20 antibody) are shown in parts (C) and $(\mathbf{D})$, respectively. The drug-damaged animal was killed 2 days $(2 d)$ after the drug injections. The white lines in $(\mathbf{C})$ and (D) delineate the region under the OHCs. C Normal animal. Brightest point projection from a confocal $Z$ series stack where the plane of the confocal section passes through Deiters' cell membranes near the basal regions of the cells. Membrane-specific Jagged1 labeling of SCs can be seen. D Drug-damaged animal. The plane of the confocal section passes through Deiters' cell membranes. Scale bar in (B) equals $50 \mu \mathrm{m}$ and applies to panels (A-B). Scale bar in (D) equals $20 \mu \mathrm{m}$ and applies to panels (C-D). $B$ Border cells; $C$ Claudius cells; $D$ Deiters' cells; $H$ Hensen's cells; IS inner sulcus; IP inner pillar; $O P$ outer pillar; SL spiral limbus; SM scala media; ST scala tympani.

post-lesion. Pillar and Deiters' cells remain in the organ, as evidenced by the distinctive actin-microtubular intracellular filament bundles identifiable within these cell types in the damaged organ (e.g., Fig. 3D) and the characteristic morphological shape of the remaining pillar cells. Either additional time is required with our lesion paradigm before marked SC degeneration occurs, or other mechanisms such as the IHCs/ associated nerve endings can provide sufficient trophic factors for the sustenance of the Deiters' cells and other SC subtypes and prevent their dedifferentiation into a less-differentiated state. The retention of the SCs may enhance neuronal survival (Sugawara et al. 2005).

\section{Are inner ear support cells stem-like cells?}

Support cells in the neonatal and mature organ of Corti are normally quiescent and unable to reenter the cell cycle after insult (Sobkowicz et al. 1992, 1997; Roberson and Rubel 1994; Chardin and Romand 1995; Zine and de Ribaupierre 1998). A variety of morphologically distinct SC types exist in the mature organ of Corti, and some subtypes are highly differentiated (e.g., pillar and Deiters' cells). This high level of differentiation has raised concerns that SCs in the mature organ of Corti may be too highly differentiated to reenter the cell cycle in response to HC damage. However, recent findings suggest stem/ progenitor cells may be present in the neonatal organ of Corti. SCs are able to divide in this tissue after certain experimental manipulations, including dissociation and culture with mitogenic growth factors (Malgrange et al. 2002; Doetzlhofer et al. 2004; White et al. 2006; Savary et al. 2007). It is not known whether dissociated cells in the mature organ of Corti possess similar proliferative capabilities. This organ is known to loose its capacity for sphere formation during the third postnatal week, suggesting a loss of stem cells or stem cell features by this time (Oshima et al. 2007).

Targeted deletions of cell cycle regulatory genes have revealed the potential of some postnatal organ of Corti SCs to reenter the cell cycle and to proliferate. Deletion of the cyclin-dependent kinase inhibitor, $p 27^{\text {Kip } 1}$, in mice leads to production of supernumerary cells in the organ of Corti through excessive mitoses that extend significantly past the normal developmental period (Chen and Segil 1999; Löwenheim et al. 1999). Two other cell cycle regulatory genes, $p 19^{\text {Ink4d }}$ and retinoblastoma, are also necessary for normal developmental cell cycle exit in the organ of Corti (Chen et al. 2003; Sage et al. 2005; Mantela et al. 2005). Deletion of either gene leads to highly disregulated DNA synthesis, including DNA synthesis in mature HCs. These studies demonstrate that some proliferative potential is retained among SCs in the postnatal organ of Corti, although it is severely restricted under normal conditions.

Several lines of evidence also suggest that inner-ear stem cells may be present in the mature mammalian vestibular SE, but in a quiescent or restricted state. Limited levels of mitotic activity occur in vestibular SCs after aminoglycoside-induced HC damage (Warchol et al. 1993; Lambert 1994; Rubel et al. 1995; Oesterle et al. 2003), and growth factors that are mitogenic for stem/progenitor cells in other systems (e.g., epidermal growth factor, transforming growth factor- $\alpha$, insulinlike growth factor-1) stimulate proliferation of mature mammalian vestibular SCs (Yamashita and Oesterle 1995). This proliferation leads to the production of small numbers of new SCs and, possibly, new HCs, in adult mammalian vestibular SE (Warchol et al. 1993; Lambert 1994; Yamashita and Oesterle 1995; Kuntz and Oesterle 1998; Oesterle et al. 2003). Furthermore, cells isolated from adult mouse utricular SE contain multipotent self-renewing cells that can generate cells with HC characteristics (Li et al. 2003a, b; Oshima et al. 2007). Taken together, these data suggest the presence of rare inner ear stem/progenitor cells in adult mammalian vestibular $\mathrm{SE}$.

We observed Sox2 expression in virtually all SCs in the adult organ of Corti and vestibular SE. Is this expression indicative of stem cell potential in these cells? Sox2 is a known marker for stem/precursor cells in a variety of tissues at different stages of development, including stem cells in neurogenic regions of the adult central nervous system and sensory retinal and taste bud precursors (Van Raay et al. 2005; Taranova et al. 2006; Okubo et al. 2006). Sox2 has been proposed to act as a universal neural stem cell marker and play a global role in maintaining progenitor/stem cell fates in a wide variety of tissues throughout lifespan (Ellis et al. 2004; Brazel et al. 

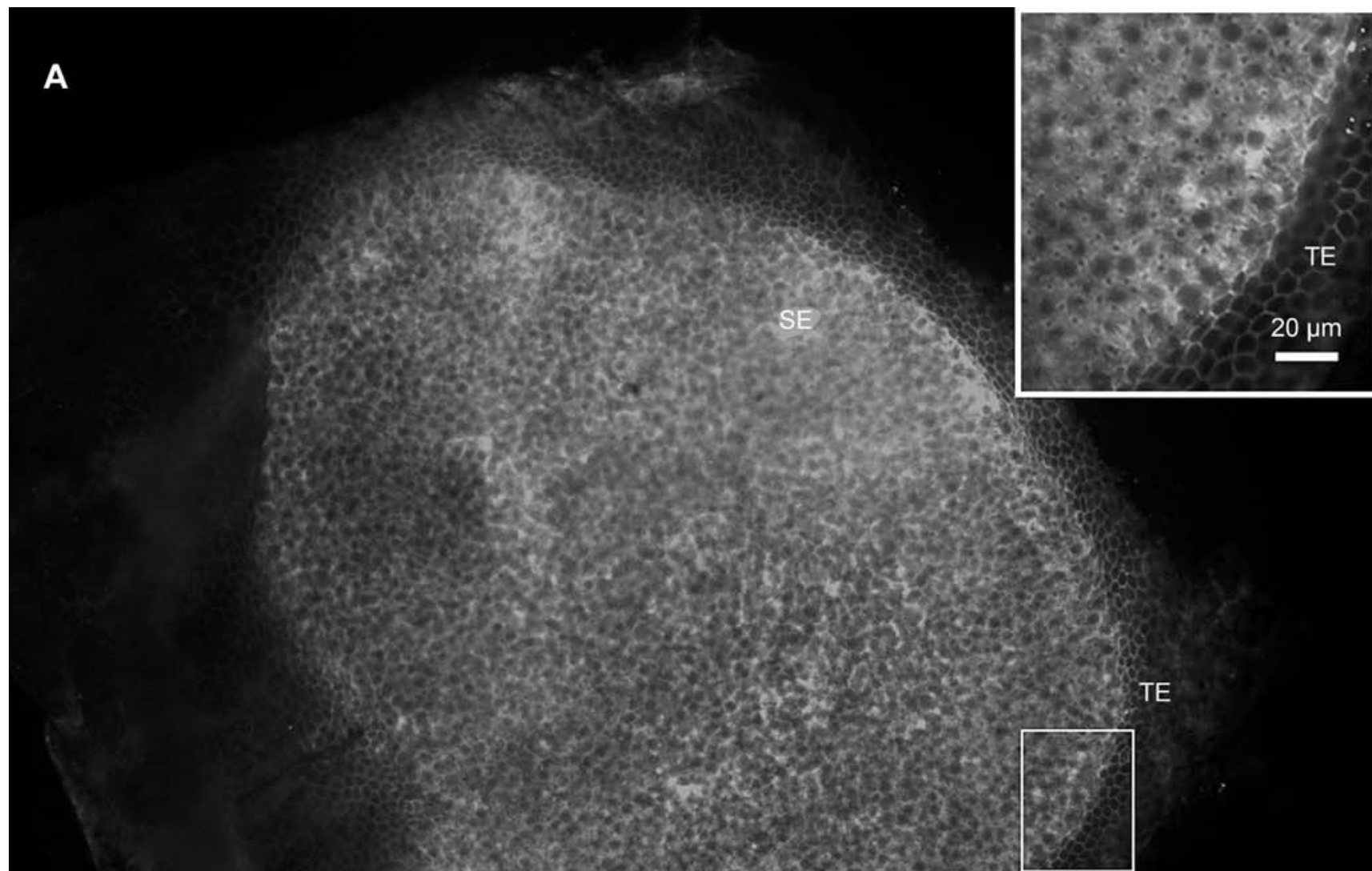

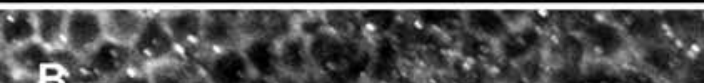

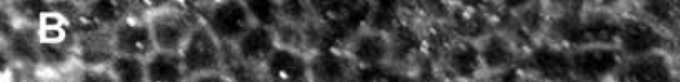

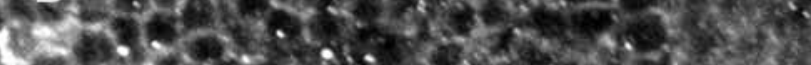

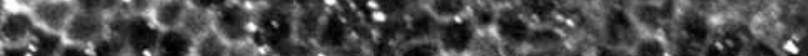

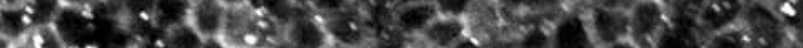

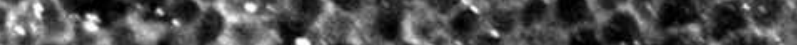

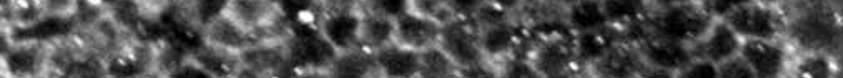

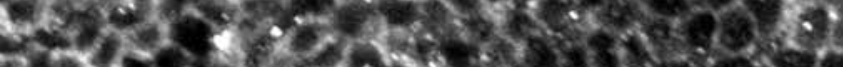

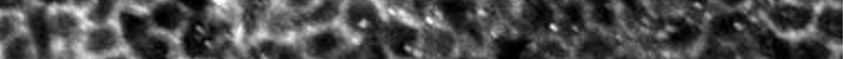

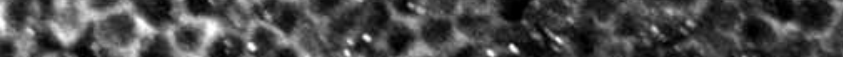

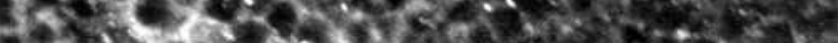

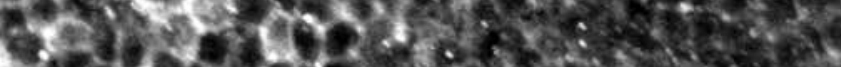

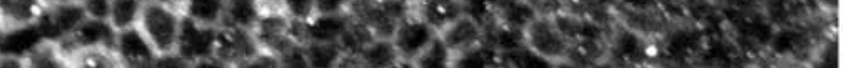

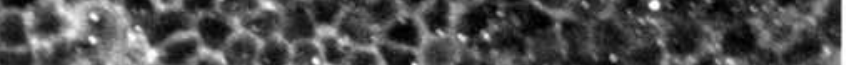

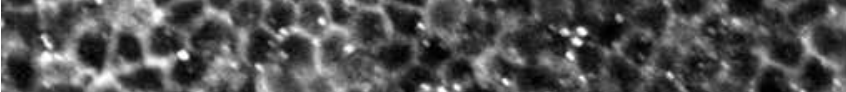

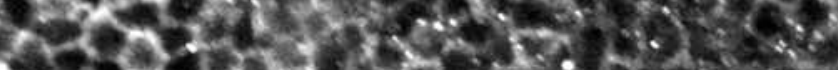
bos.

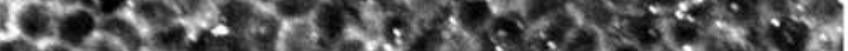

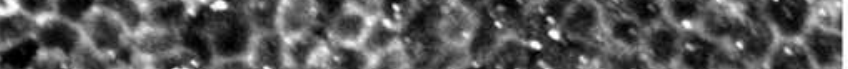

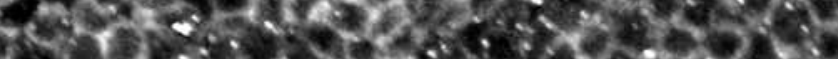

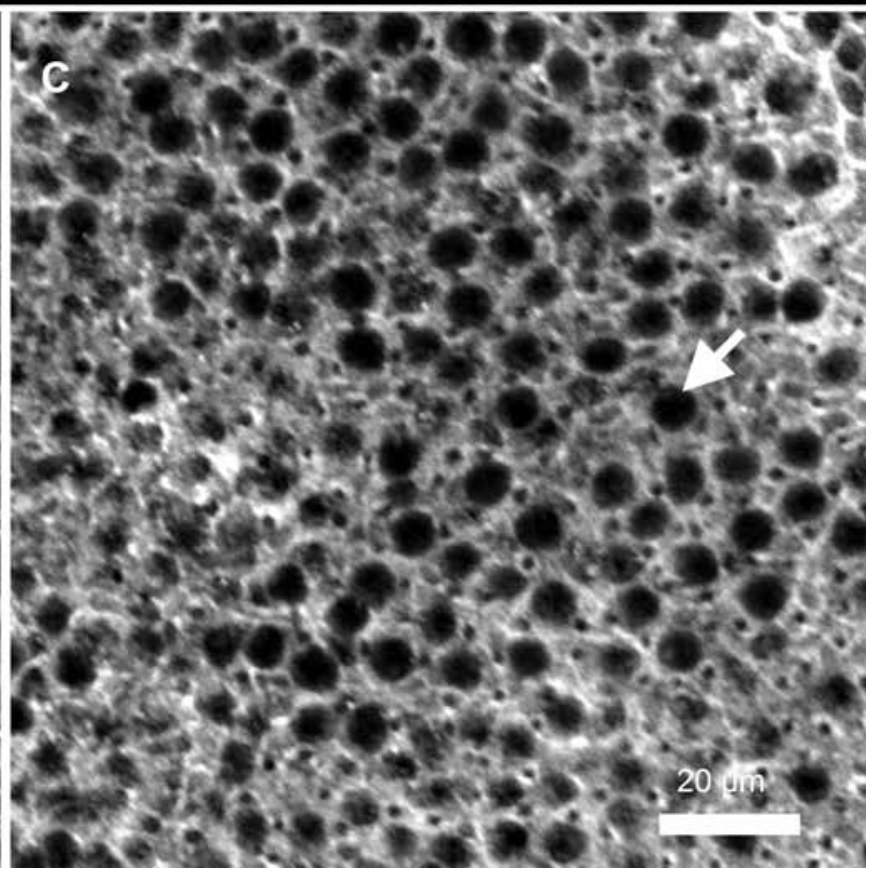


FIG. 12. Jagged 1 expression in normal adult mouse utricle. Wholemount preparations of adult utricular macula immunostained for Jagged1. The entire macula is shown in (A), and the boxed region is shown at higher magnification in the inset, where the focal plane is near the reticular lamina. Jagged1 labels SC membranes throughout the macula. Jagged1 also labels the membranes of transitional epithelial cells. B-C Brightest point projections from a confocal $Z$ series spanning the depth of the sensory epithelium. $Z$ levels near the SC nuclear layer are shown in (B), and a level near the reticular lamina is shown in (C). Hair cells appear as large black holes (arrow in C). SE Sensory epithelium; TE transitional epithelium. Scale bars for (A) and its inset equal 100 and $20 \mu \mathrm{m}$, respectively. The scale bar in $(\mathbf{C})$ equals $20 \mu \mathrm{m}$ and applies to panels (B-C).

2005). However, Sox2 is known to be persistently expressed in differentiated neurons in the adult brain, in subtypes of postmitotic neurons, including pyramidal cells of the cerebral cortex, some striatal neurons and many thalamic neurons (Ferri et al. 2004). Sox2's presence in these cells indicates it may play roles other than stem cell/progenitor roles in adult tissues. Sox 2 is postulated to play a role in neuronal cell function and maintenance for selected areas in the adult brain (Ferri et al. 2004; reviewed in Lang 2004; Kondoh et al. 2004; Episkopou 2005; Wegner and Stolt 2005; Steiner et al. 2006).

Given the limited proliferative capabilities of mammalian SCs in the mature ear, our finding that Sox2 is expressed by virtually all inner ear SCs is surprising and appears incongruent with the idea that Sox2 marks stem cells in this tissue and plays a role in the maintenance of a stem-cell like fate. Instead, one might anticipate a highly limited stem/precursor cell distribution in adult mammalian inner ear tissues. Alternatively, Sox2 may not be involved in maintaining a stem cell-like state in the SCs, but rather in the maintenance of the SCs and/or their function. It is also possible that a combination of both of these exists, a role for stem-cell maintenance in a subset of the cells and a role in SC function and maintenance in another subset of SCs. Our finding that Sox2 is expressed in a subset of vestibular HCs, a highly differentiated cell type without proliferative capacities and for which precursor cell properties cannot be assumed, further suggests Sox2 has roles besides stem cell functioning in mature inner ear tissues. Clearly, future work is needed to delineate Sox2's roles in the adult inner ear. Experiments characterizing the expression of other members of the Sox family in adult inner ear SE are needed, as are experiments that manipulate the levels of Sox2 expression in specific inner ear cell types (e.g., loss of function, gain of function, and conditional ablation studies). These experiments will no doubt shed light on the maintenance and stem cell functions of this protein in the adult inner ear.

\section{Does Sox2 label type II HCs?}

Sox2 labels a subset of vestibular HCs, in both the striolar and extrastriolar regions. Within the striolar/ juxtastriolar region, the Sox2-labeled HCs are not contacted by large calbindin-positive calyx endings, suggesting they are Type II HCs. An additional observation linking the Sox2-positive HCs to Type II HCs is that the Sox2-positive HC nuclei tend to be located slightly higher (closer to lumen) in the epithelium than the nuclei of the Sox2-negative HCs. Nuclei of Type II HCs are reported to be positioned closer to the lumen than Type I HC nuclei, which are generally located just above the SC nuclei (Desai et al. 2005).

Our estimates of total HC density (striola, $1.4 \pm 0.3 \mathrm{HC}$ ) $100 \mu \mathrm{m}^{2} \mathrm{SE}[\mathrm{mean} \pm \mathrm{SD}$ ]; extrastriolar, $1.7 \pm 0.4)$ agree well with those reported by Desai et al. (2005) for adult CBA/J mice (striola, $1.6 \pm 0.05 \mathrm{HC} / 100 \mu \mathrm{m}^{2} \mathrm{SE}$ $[$ mean \pm SE]; extrastriolar, $1.7 \pm 0.09)$. Roughly equivalent numbers of Sox2-negative and Sox2-positive HCs were observed in the striolar/juxtastriolar region, a ratio of $1.1 \pm 0.2$ Sox2-negative to Sox2-positive HCs. Our data do not support the idea that there are twice as many Type I HCs in the striola region compared with Type II HCs; a 2:1 ratio was proposed by earlier studies (Engström and Wersäll 1958; Lindeman 1969; Watanuki and Meyer zum Gottesberge 1971). Our ratio is also lower than the $1.5 \pm 0.02($ mean \pm SE) Type $1 /$ Type II ratio reported by Desai et al. (2005). The inclusion of juxtastriolar cells in our analysis may account for some of the discrepancy, as Desai et al. (2005) quantified the striolar region specifically, not the larger striolar/juxtastriolar region. An alternative explanation is that Sox2 labeling does not fully delineate Type I from Type II HCs.

In the extrastriolar regions of the utricular macula, both Sox2-positive and Sox2-negative HCs are present, with a ratio of $1.5 \pm 0.3$ Sox2- to Sox $2+$ HCs. This is suggestive of a 1.5 Type I/Type II HC ratio in the extrastriolar region of the utricular macula. The two kinds of HCs have been reported to occur in nearly equal numbers in the extrastriolar regions of mammalian otolithic organs (Engström and Wersäll 1958; Lindeman 1969; Watanuki and Meyer zum Gottesberge 1971), and a Type 1/Type II ratio of $1.2 \pm 0.01 \quad($ mean $\pm \mathrm{SE})$ was reported by Desai et al. (2005).

We used utricles double-labeled for Sox2 and calbindin to estimate numbers of Type I and Type II HCs in the utricle and made the assumption that all cells within the HC nuclear layer are HCs. This assumption was based on two findings: (1) There is no ongoing production of new cells in the adult mammalian utricle; hence, cells in the process of dividing are absent from the $\mathrm{HC}$ layer in this tissue (Yamashita and Oesterle 1995; Kuntz and Oesterle 1998); and (2) our double-labeling experiments for 
myosin and Sox2 indicated that Sox2-negative cells in the HC laver are HCs. We cannot rule out the possibility of a rare Sox2-negative non-HC being present in the HC nuclear layer. However, we would argue that the rarity of such a cell would not lead to a significant overestimation of the number of Sox2negative (Type I) HCs. Our estimates of striolar Type I HCs, as discussed above, are lower, not higher, than those reported by Desai et al. (2005), and our estimates of total HC density agree.

At present, it is difficult to speculate regarding the functional role Sox2 plays in vestibular HCs in the adult ear. As mentioned above, Sox2 is expressed in a subset of differentiated neurons in the adult brain, and it has been suggested that it may play a role in neuronal function and maintenance (Ferri et al. 2004; Episkopou 2005).

In conclusion, we have developed several useful tools for studying $\mathrm{HC}$ regeneration in mature mice. The single high-dose injection of the aminoglycoside kanamycin followed with a single injection of the loop diuretic furosemide results in rapid OHC death throughout virtually the entire cochlea of the adult mouse. Studies examining the time course of the drug-induced changes can be now readily undertaken, because of the rapid, synchronized, and reliable lesion. We identified two markers of adult SCs, Sox2 and Jagged1, that may be useful to assess responses of SCs to HC damage. The transcription factor Sox2 is expressed specifically in SCs in the normal and drugdamaged adult mouse inner ear. Sox2 immunoreactivity is found in auditory and vestibular SCs and a subset of vestibular HCs, type II HCs. The Notch ligand, Jagged1, is expressed in vestibular and auditory SCs in the adult mouse. Despite the extensive loss of auditory OHCs in our aminoglycoside-induced injury model, the expression of Sox2 and Jagged1 in SCs appear unaffected.

\section{ACKNOWLEDGMENTS}

Many thanks to Drs. Olivia Berminham-McDonogh, Jennifer Stone, David Rabile, and Ed Rubel for helpful conversations and encouragement, Dale Cunningham for plastic sectioning, Glenn MacDonald for help with ImageJ, and Chad Soden for help with cell counts. This research was supported by an NIDCD R01 grant DC03944 (EO), NIDCD P30 grant DC04661, NICHHD P30 grant HD002274, and the Hearing Regeneration Initiative.

\section{REFERENCES}

Adam J, Myat A, Le Roux I, Eddison M, Henrigue D, Ish-Horowicz D, LEWIS J. Cell fate choices and the expression of Notch, Delta and Serrate homologues in the chick inner ear: parallels with
Drosophila sense-organ development. Development 125 (23):4645-4654, 1998 .

Adler HJ, Raphael Y. New hair cells arise from supporting cell conversion in the acoustically damaged chick inner ear. Neurosci. Lett. 205(1):17-20, 1996.

Aran JM, Chappert C, Dulon D, Erre JP, Aurousseau C. Uptake of amikacin by hair cells of the guinea pig cochlea and vestibule and ototoxicity: comparison with gentamicin. Hear. Res. 82 (2):179-183, 1995.

Baird RA, Steyger PS, Schuff N. Mitotic and nonmitotic hair cell regeneration in the bullfrog vestibular otolith organs. Ann. NY Acad. Sci. 781:59-70, 1996.

Bermingham-McDonogh O, Rubel EW. Hair cell regeneration: winging our way towards a sound future. Curr. Opin. Neurobiol. 13(1):119126, 2003.

Bichler E, Spoendlin H, Rauchegger H. Degeneration of cochlear neurons after amikacin intoxication in the rat. Arch. Otorhinolaryngol. 237(3):201-208, 1983.

Brazel Cy, Limke Tl, Osborne JK, Miura T, Cai J, Pevny L, Rao MS. Sox2 expression defines a heterogeneous population of neurosphere-forming cells in the adult murine brain. Aging Cell 4 (4):197-207, 2005.

Brooker R, Hozumi K, Lewis J. Notch ligands with contrasting functions: Jagged 1 and Delta1 in the mouse inner ear. Development 133(7):1277-1286, 2006.

BROWN RD, McELWEE TW JR. Effects of intra-arterially and intravenously administered ethacrynic acid and furosemide on cochlear N 1 in cats. Toxicol. Appl. Pharmacol. 22(4):589-594, 1972.

Brummett RE, Traynor J, Brown R, Himes D. Cochlear damage resulting from kanamycin and furosemide. Acta Otolaryngol. 80 (1-2):86-92, 1975.

Brummett RE, Bendrick T, Himes D. Comparative ototoxicity of bumetanide and furosemide when used in combination with kanamycin. J. Clin. Pharmacol. 21(11-12 Pt 2):628-636, 1981.

Bryant GM, Renard N, Rebillard G. Excitotoxicity in the guinea pig cochlea. Assoc. Res. Otolaryngol. 11:39, 1987.

Chardin S, Romand R. Regeneration and mammalian auditory hair cells. Science 267(5198):707-711, 1995.

Chen CS, SAunders JC. The sensitive period for ototoxicity of kanamycin in mice: morphological evidence. Arch. Otorhinolaryngol. 238 (3):217-223, 1983.

Chen P, SegIL N. p27 ${ }^{\text {Kip } 1}$ links cell proliferation to morphogenesis in the developing organ of Corti. Development 126:1581-1590, 1999.

Chen P, Johnson JE, Zoghbi HY, Segil N. The role of Math1 in inner ear development: Uncoupling the establishment of the sensory primordium from hair cell fate determination. Development 129 (10):2495-2505, 2002.

Chen P, Zindy F, Abdala C, Liu F, Li X, Roussel MF, Segil N. Progressive hearing loss in mice lacking the cyclin-dependent kinase inhibitor Ink4d. Nat. Cell Biol. 5(5):422-426, 2003.

Chu HQ, Xiong H, Zhou XQ, Han F, Wu ZG, Zhang P, Huang XW, Cur YH. Aminoglycoside ototoxicity in three murine strains and effects on NKCC1 of stria vascularis. Chin. Med. J. 119(12):980985, 2006.

CoRwin JT, Cotanche DA. Regeneration of sensory hair cells after acoustic trauma. Science 240:1772-1774, 1988.

Crouch JJ, Sakaguchi N, Lytle C, Schulte BA. Immunohistochemical localization of the $\mathrm{Na}-\mathrm{K}-\mathrm{Cl}$ co-transporter (NKCC1) in the gerbil inner ear. J. Histochem. Cytochem. 45(6):773-778, 1997.

Cunningham LL, Cheng AG, Rubel EW. Caspase activation in hair cells of the mouse utricle exposed to neomycin. J. Neurosci. 22 (19):8532-8540, 2002.

De Groot JC, Huizing EH, Veldman JE. Ultrastructural localization of gentamicin in the cochlea. Hear. Res. 50(1-2):35-42, 1990.

Dechesne CJ, Thomasset M. Calbindin (CaBP $28 \mathrm{kDa}$ ) appearance and distribution during development of the mouse inner ear. Brain Res. 468:233-242, 1988. 
Dechesne CJ, Thomasset M, Brehier A, Sans A. Calbindin (CaBP $28 \mathrm{kDa}$ ) localization in the peripheral vestibular system of various vertebrates. Hear. Res. 33:273-278, 1988.

Dechesne CJ, Rabejac D, Desmadryl G. Development of calretinin immunoreactivity in the mouse inner ear. J. Comp. Neurol. 346 (4):517-529, 1994.

Desai SS, Zeh C, Lysakowski A. Comparative morphology of rodent vestibular periphery. I. Saccular and utricular maculae. J. Neurophysiol. 93(1):251-266, 2005.

Doetzlhofer A, White PM, Johnson JE, Segil N, Groves AK. In vitro growth and differentiation of mammalian sensory hair cell progenitors: a requirement for EGF and periotic mesenchyme. Dev. Biol. 272(2):432-447, 2004.

Ellis P, Fagan BM, Magness St, Hutton S, Taranova O, Hayashi S, McMahon A, Rao M, Pevny L. SOX2, a persistent marker for multipotential neural stem cells derived from embryonic stem cells, the embryo or the adult. Dev. Neurosci. 26(2-4):148$165,2004$.

ENGSTRÖM H, WeRSÄLl J. Structure and innervation of the inner ear sensory epithelia. Int. Rev. Cytol. 7:535-585, 1958.

EpIsKopou V. SOX2 functions in adult neural stem cells. Trends Neurosci. 28(5):219-221, 2005.

Evans EF, KuInkE R. The effects of intracochlear and systemic furosemide on the properties of single cochlear nerve fibres in the cat. J. Physiol. 331:409-427, 1982.

Farris HE, LeBlanc CL, Goswami J, Ricci AJ. Probing the pore of the auditory hair cell mechanotransducer channel in turtle. J. Physiol. 558(Pt 3):769-792, 2004.

Ferri AL, Cavallaro M, Braida D, Di Cristofano A, Canta A, Vezzani A, Ottolenghi S, Pandolfi PP, Sala M, DeBiasi S, Nicolis SK. Sox2 deficiency causes neurodegeneration and impaired neurogenesis in the adult mouse brain. Development 131(15):38053819, 2004.

Forge A, Brown AM. Ultrastructural and electrophysiological studies of acute ototoxic effects of furosemide. Br. J. Audiol. 16(2):109116,1982

Forge A, Schacht, J. Aminoglycoside antibiotics. Audiol. NeuroOtol. 5(1):3-22, 2000.

FREDELIUS L. Time sequence of degeneration pattern of the organ of Corti after acoustic overstimulation. A transmission electron microscopy study. Acta Otolaryngol. 106(5-6):373-385, 1988.

Fredelius L, Rask-Andersen H, Johansson B, Urquiza R, BaggerSJoback D, Wersall J. Time sequence of degeneration pattern of the organ of Corti after acoustic overstimulation. A light microscopical and electrophysiological investigation in the guinea pig. Acta Otolaryngol. 106(1-2):81-93, 1988.

Hackney CM, Mahendrasingam S, Penn A, Fettiplace R. The concentrations of calcium buffering proteins in mammalian cochlear hair cells. J. Neurosci. 25(34):7867-75. J. Neurosci. 25 (34):7867-7886, 2005.

Hagstrom Sa, Pauer GJ, Reid J, Simpson E, Crowe S, Maumenee iH, Traboulsi EI. SOX2 mutation causes anophthalmia, hearing loss, and brain anomalies. Am. J. Med. Genet. A. 138(2):95-98, 2005.

HAsSon T, Mooseker MS. Porcine myosin-VI: characterization of a new mammalian unconventional myosin. J. Cell Biol. 127 (2):425-440, 1994

Hasson T, Heintzelman MB, Santos-Sacchi J, Corey DP, Mooseker MS. Expression in cochlea and retina of myosin VIIa, the gene product defective in Usher syndrome type 1B. Proc. Natl. Acad. Sci. U. S. A. 92(21):9815-9819, 1995.

Hasson T, Gillespie PG, Garcia JA, MacDonald RB, Zhao Y, Yee AG, Mooseker MS, Corey DP. Unconventional myosins in inner-ear sensory epithelia. J. Cell Biol. 137(6):1287-1307, 1997.

HE DZ, JiA S, Dallos P. Mechanoelectrical transduction of adult outer hair cells studied in a gerbil hemicochlea. Nature 429 (6993):766-770, 2004
Henry KR, Chole RA, McGinn MD, Frush DP. Increased ototoxicity in both young and old mice. Arch. Otolaryngol. 107(2):92-95, 1981.

Heydt JL, Cunningham LL, Rubel EW, Coltrera MD. Round window gentamicin application: an inner ear hair cell damage protocol for the mouse. Hear. Res. 192(1-2):65-74, 2004.

Hume CR, Bratt DL, Oesterle EC. Expression of LHX3 and SOX2 during mouse inner ear development. Gene Expr. Patterns 7 (7):798-807, 2007.

Humes HD. Insights into ototoxicity. Analogies to nephrotoxicity. Ann. N. Y. Acad. Sci. 884:15-18, 1999.

Imamura S, Adams JC. Distribution of gentamicin in the guinea pig inner ear after local or systemic application. J. Assoc. Res. Otolaryngol. 4(2):176-195, 2003.

Izumikawa M, Minoda R, Kawamoto K, Abrashimin KA, Swiderski DL, Dolan DF, BRough DE, RaphaEL Y. Auditory hair cell replacement and hearing improvement by Atoh 1 gene therapy in deaf mammals. Nature Med. 11:271-276, 2005.

Jiang H, Sha SH, Sснаснт J. NF-kappaB pathway protects cochlear hair cells from aminoglycoside-induced ototoxicity. J. Neurosci. Res. 79(5):644-651, 2005.

Jiang H, Sha SH, Forge A, Schacht J. Caspase-independent pathways of hair cell death induced by kanamycin in vivo. Cell Death Differ. 13(1):20-30, 2006a.

Jiang H, Sha SH, Schacht J. Kanamycin alters cytoplasmic and nuclear phosphoinositide signaling in the organ of Corti in vivo. J. Neurochem. 99(1):269-276, 2006b.

Jones JM, Montcouquiol M, Dabdoub A, Woods C, Kelley MW. Inhibitors of differentiation and DNA binding (Ids) regulate Math1 and hair cell formation during the development of the organ of Corti. J. Neurosci. 26(2):550-558, 2006.

Kelley MW. Regulation of cell fate in the sensory epithelia of the inner ear. Nat. Rev. Neurosci. 7(11):837-849, 2006a

KELLEY MW. Hair cell development: commitment through differentiation. Brain Res. 1091(1):172-185, 2006b.

Kiernan Ae, Pelling Al, Leung KK, Tang as, Bell DM, Tease C, Lovell-Badge R, Steel KP, Cheah KS. Sox2 is required for sensory organ development in the mammalian inner ear. Nature 434 (7036):1031-1035, 2005a.

Kiernan AE, Cordes R, Kopan R, Gossler A, Gridley T. The Notch ligands DLL1 and JAG2 act synergistically to regulate hair cell development in the mammalian inner ear. Development 132 (19):4353-4362, 2005b.

Kiernan AE, Xu J, Gridley T. The Notch ligand JAG1 is required for sensory progenitor development in the mammalian inner ear. PLoS Genet. 2(1):e4, 2006.

Köhler C, Bell AW, Bowen WC, Monga SP, Fleig W, MichalopouLOS GK. Expression of Notch-1 and its ligand Jagged-1 in rat liver during liver regeneration. Hepatology 39(4):1056-1065, 2004.

Kondoh H, UchiKaWa M, Kamachi Y. Interplay of Pax6 and SOX2 in lens development as a paradigm of genetic switch mechanisms for cell differentiation. Int. J. Dev. Biol. 48(8-9):819-827, 2004.

Kros CJ, Rusch A, Richardson GP. Mechano-electrical transducer currents in hair cells of the cultured neonatal mouse cochlea. Proc. Biol. Sci. 249(1325):185-193, 1992.

Kuntz AL, Oesterle EC. Transforming growth factor alpha with insulin stimulates cell proliferation in vivo in adult rat vestibular sensory epithelium. J. Comp. Neurol. 399:413-423, 1998.

Kusakari J, Ise I, Comegrs TH, Thalmann I, Thalmann R. Effect of ethacrynic acid, furosemide, and ouabain upon the endolymphatic potential and upon high energy phosphates of the stria vascularis. Laryngoscope 88(1 Pt 1):12-37, 1978a.

Kusakari J, Kambayashi J, Ise I, Kawamoto K. Reduction of the endocochlear potential by the new "loop" diuretic, bumetanide. Acta. Otolaryngol. 86(5-6):336-341, 1978b. 
LAMBERT PR. Inner ear hair cell regeneration in a mammal: identification of a triggering factor. Laryngoscope 104:701-718, 1994.

LANG RA. Pathways regulating lens induction in the mouse. Int. J. Dev. Biol. 48(8-9):783-791, 2004.

Lenoir M, Daudet N, Humbert G, Renard N, Gallego M, Pujol R, Eybalin M, Vago P. Morphological and molecular changes in the inner hair cell region of the rat cochlea after amikacin treatment. J. Neurocytol. 28(10-11):925-937, 1999.

LeONARD RB, KeVETter GA. Molecular probes of the vestibular nerve. I. Peripheral termination patterns of calretinin, calbindin and peripherin containing fibers. Brain Res. 928(1-2):8-17, 2002.

Li, H, Liu H, Heller, S. Pluripotent stem cells from the adult mouse inner ear. Nature Med. 9(10):1293-1299, 2003a.

Li H, Roblin G, Liu H, Heller S. Generation of hair cells by stepwise differentiation of embryonic stem cells. Proc. Natl. Acad. Sci. U. S. A. 100(23):13495-13500, 2003b.

Lim DJ, RuEDa J. Structural development of the cochlea. In: Romand $\mathrm{R}$ (ed) Development of auditory and vestibular systems 2 . Elsevier Science, pp. 33-58, 1992.

LiNDEMAN HH. Studies on the morphology of the sensory regions of the vestibular apparatus. Ergeb Anat Entwicklungsgesch. 42 (1):1-113, 1969.

Lopez IA, Zhao PM, Yamaguchi M, de Vellis J, Espinosa-Jeffrey A. Stem/progenitor cells in the postnatal inner ear of the GFPnestin transgenic mouse. Int. J. Dev. Neurosci. 22(4):205-213, 2004.

Lönenheim H, Furness, DN, Kil J, Zinn C, Gültig, K, Fero ML, Frost D, Gummer AW, Roberts JM, Rubel EW, Hackney CM, Zenner HP. Proc. Nat. Acad. Sci. U. S. A. 96:4084-4088, 1999.

Malgrange B, Belachew S, Thiry M, Nguyen L, Rogister B, Alvarez M, Rigo J-M, Van De Water TR, Moonen G, Lefebvre PP. Proliferative generation of mammalian auditory hair cells in culture. Mechanisms Dev. 112:79-88, 2002.

Mantela J, Jiang Z, Ylikoski J, Fritzsch B, Zacksenhaus E, Pirvola U. The retinoblastoma gene pathway regulates the postmitotic state of hair cells of the mouse inner ear. Development 132:23772388, 2005.

Marcotti W, van Netten SM, Kros CJ. The aminoglycoside antibiotic dihydrostreptomycin rapidly enters mouse outer hair cells through the mechano-electrical transducer channels. J. Physiol. 567(Pt 2):505-521, 2005.

Mathog RH, Klein WJ JR. Ototoxicity of ethacrynic acid and aminoglycoside antibiotics in uremia. N. Engl. J. Med. 280 (22):1223-1224, 1969.

Matsui JI, Cotanche DA. Sensory hair cell death and regeneration: two halves of the same equation. Curr. Opin. Otolaryngol. Head Neck Surg. 12(5):418-425, 2004.

Matsui Ji, Parker MA, Ryals BM, Cotanche DA. Regeneration and replacement in the vertebrate inner ear. Drug Discov. Today 10 (19):1307-1312, 2005.

Meriwether WD, Mangi RJ, Serpick AA. Deafness following standard intravenous dose of ethacrynic acid. JAMA 216(5):795-798, 1971.

Mizuta K, ADACHi M, IwaSA KH. Ultrastructural localization of the $\mathrm{Na}-\mathrm{K}-\mathrm{Cl}$ cotransporter in the lateral wall of the rabbit cochlear duct. Hear. Res. 106(1-2):154-162, 1997.

Montcouguiol M, Kelley MW. Planar and vertical signals control cellular differentiation and patterning in the mammalian cochlea. J. Neurosci. 23(28):9469-9478, 2003.

Morrison A, Hodgetts C, Gossler A, Hrabe de Angelis M, Lewis J. Expression of Delta1 and Serrate1 (Jagged1) in the mouse inner ear. Mech. Dev. 84(1-2):169-172, 1999.

Murata J, Tokunaga A, Okano H, Kubo T. Mapping of notch activation during cochlear development in mice: implications for determination of prosensory domain and cell fate diversification. J. Comp. Neurol. 497(3):502-518, 2006.
Nakai Y, Chang KC, Ohashi K, Morisaki N. Ototoxic effect of an aminoglycoside drug on an immature inner ear. Acta Otolaryngol Suppl. 393:1-5, 1983.

Oesterle EC, Stone JS. Hair cell regeneration: cellular proliferation and cell fate acquistion. In: Fay, RR, Popper, AN, and Salvi, R (eds) Regeneration and Repair of the Auditory System. Springer Handbook of Auditory Research series (in press), 2008.

Oesterle EC, Sarthy PV, Rubel EW. Intermediate filaments in the inner ear of normal and experimentally damaged guinea pigs. Hear. Res. 47(1-2):1-16, 1990.

Oesterle EC, Cunningham DE, Westrum Le, Rubel EW. Ultrastructural analysis of $\left({ }^{3} \mathrm{H}\right)$ thymidine-labeled cells in the rat utricular macula. J. Comp. Neurol. 463:177-195, 2003.

Oesterle EC, Campbell S, Taylor R, Forge A, Hume C. Sox2 and Jagged1 expression in adult mouse inner ear sensory epithelia. Assoc. Res. Otolaryngol. Abstr. 30:186, 2007.

Oкubo T, Pevny LH, Hogan BL. Sox2 is required for development of taste bud sensory cells. Genes Dev. 20(19):2654-2659, 2006.

Oshima K, Grimm CM, Corrales CE, Senn P, Martinez Monedero R, Geleoc GS, Edge A, Holt JR, Heller S. Differential distribution of stem cells in the auditory and vestibular organs of the inner ear. J. Assoc. Res. Otolaryngol. 8:18-31, 2007.

PIKE DA, Bosher SK. The time course of the strial changes produced by intravenous furosemide. Hear. Res. 3(1):79-89, 1980.

Prieve BA, Yanz, JL. Age-dependent changes in susceptibility to ototoxic hearing loss. Acta Otolaryngol. 98(5-6):428-438, 1984.

Raphael Y, Altschuler RA. Scar formation after drug-induced cochlear insult. Hear. Res. 51:173-184, 1991.

Raymond J, Dechesne CJ, Desmadryl G, Dememes D. Different calciumbinding proteins identify subpopulations of vestibular ganglion neurons in the rat. Acta Otolaryngol. Suppl. 503:114-118, 1993.

Richardson GP, Forge A, Kros CJ, Fleming J, Brown SD, Steel KP. Myosin VIIA is required for aminoglycoside accumulation in cochlear hair cells. J. Neurosci. 17(24):9506-9519, 1997.

Richardson GP, Forge A, Kros CJ, Marcotti W, Becker D, Williams DS, Thorpe J, Fleming J, Brown SD, Steel KP. A missense mutation in myosin VIIA prevents aminoglycoside accumulation in early postnatal cochlear hair cells. Ann. N. Y. Acad. Sci. 884:110-124, 1999.

Roberson DW, Rubel EW. Cell division in the gerbil cochlea after acoustic trauma. Am. J. Otol. 15(1):28-34, 1994.

Roberson DW, Kreig CS, Rubel EW. Light microscopic evidence that direct transdifferentiation gives rise to new hair cells in regenerating avian auditory epithelium. Aud. Neurosci. 2:195205, 1996.

Roberson DW, Alosi JA, Cotanche DA. Direct transdifferentiation gives rise to the earliest new hair cells in regenerating avian auditory epithelium. J. Neurosci. Res. 78(4):461-471, 2004.

Rubel EW, Dew LA, Roberson DW. Mammalian vestibular hair cell regeneration. Science 267:701-707, 1995.

Ruggero MA, Rich NC. Furosemide alters organ of corti mechanics: evidence for feedback of outer hair cells upon the basilar membrane. J. Neurosci. 11(4):1057-1067, 1991.

Rvals BM, RubeL EW. Hair cell regeneration after acoustic trauma in adult Coturnix quail. Science 240:1774-1776, 1988.

Sage C, Ventéo S, Jeromin A, Roder J, Dechesne CJ. Distribution of frequenin in the mouse inner ear during development, comparison with other calcium-binding proteins and synaptophysin. Hear. Res. 150(1-2):70-82, 2000.

Sage C, Huang M, Karimi K, Gutierrez G, Vollrath MA, Zhang D-S, García-Añoveros J, Hinds PW, Corwin JT, Corey DP, Chen Z-Y. Proliferation of functional hair cells in vivo in the absence of the retinoblastoma protein. Science 307:1114-1118, 2005.

SANTI PA, Duvall AJ 3RD. Morphological alteration of the stria vascularis after administration of the diuretic bumetanide. Acta Otolaryngol. 88(1-2):1-12, 1979. 
Santi PA, Lakhani BN. The effect of bumetanide on the stria vascularis: a stereological analysis of cell volume density. Hear. Res. 12(2):151-165, 1983.

Santi PA, Ruggero MA, Nelson DA, Turner CW. Kanamycin and bumetanide ototoxicity: anatomical, physiological and behavioral correlates. Hear. Res. 7(3):261-279, 1982.

Santos-SACchi J, Wu M, Kakehata S. Furosemide alters nonlinear capacitance in isolated outer hair cells. Hear. Res. 159(1-2):6973, 2001.

Savary E, Hugnot JP, Chassigneux Y, Travo C, Duperray C, Van De WATER T, Zine A. Distinct population of hair cell progenitors can be isolated from the postnatal mouse cochlea using side population analysis. Stem Cells 25(2):332-339, 2007.

Schacht J, Hawkins JE. Sketches of otohistory. Part 11: Ototoxicity: drug-induced hearing loss. Audiol. Neurootol. 11(1):1-6, 2006.

Shou J, Zheng JL, Gao WQ. Robust generation of new hair cells in the mature mammalian inner ear by adenoviral expression of Hath1. Mol. Cell Neurosci. 23(2):169-179, 2003.

Sobkowicz HM, August BK, SLApnick SM. Epithelial repair following mechanical injury of the developing organ of Corti in culture: an electron microscopic and autoradiographic study. Exp. Neurol. 115(1):44-49, 1992

Sobkowicz HM, SLAPNick SM, August BK. The kinocilium of auditory hair cells and evidence for its morphogenetic role during the regeneration of stereocilia and cuticular plates. J. Neurocytol. 24 (9):633-653, 1995.

Sobkowicz HM, August BK, SLapnick SM. Cellular interactions as a response to injury in the organ of Corti in culture. Int. J. Dev. Neurosci. 15(4-5):463-485, 1997.

Staecker H, Praetorius M, Baker K, Brough DE. Vestibular hair cell regeneration and restoration of balance function induced by math1 gene transfer. Otol. Neurotol. 28(2):223-31, 2007.

Steiner B, Klempin F, Wang L, Kott M, Kettenmann H, Kempermann G. Type-2 cells as link between glial and neuronal lineage in adult hippocampal neurogenesis. Glia 54(8):805-814, 2006.

Stone JS, Rubel EW. Deltal expression during avian hair cell regeneration. Development 126(5):961-973, 1999.

Sugawara M, Corfas G, Liberman MC. Influence of supporting cells on neuronal degeneration after hair cell loss. J. Assoc. Res. Otolaryngol. 6(2):136-147, 2005.

Taranova OV, Magness ST, Fagan BM, Wu Y, Surzenko N, Hutton SR, Pevny LH. Genes Dev. 20(9):1187-1202, 2006.

TAYLOR R, Forge, A. Hair cell regeneration in sensory epithelia from the inner ear of a urodele amphibian. J. Comp. Neurol. 484 (1):105-120, 2005.

TAYlor RR, NeVIll G, Forge, A. Rapid hair cell loss: a mouse model for auditory lesions. JARO, 2007 (in press).

Tran Ba Huy P, Manuel C, Meulemans A, Sterkers O, Wassef M, Amie C. Ethacrynic acid facilitates gentamicin entry into endolymph of the rat. Hear. Res. 11(2):191-202, 1983.

Van RaAy TJ, Moore KB, Iordanova I, Steele M, Jamrich M, Harris WA, VetTer ML. Frizzled 5 signaling governs the neural potential of progenitors in the developing Xenopus retina. Neuron 46 (1):23-36, 2005

WANGEMANN P. Comparison of ion transport mechanisms between vestibular dark cells and strial marginal cells. Hear. Res. 90 (1-2):149-157, 1995.

Warchol ME, Lambert PR, Goldstein BJ, Forge A, Corwin JT. Regenerative proliferation in inner ear sensory epithelia from adult guinea pigs and humans. Science 259(5101):1619-1622, 1993.

Watanuki K, Meyer zum Gottesberge A. Morphological observations of the sensory epithelium of the macula sacculi and utriculi in the guinea pig. Arch. Klin. Ohren-Nasen-KehlkopfheikD. 200:136-144, 1971.

Wegner M, Stolt CC. From stem cells to neurons and glia: a Soxist's view of neural development. Trends Neurosci. 28(11):583-588, 2005.

White PM, Doetzlhofer A, Lee YS, Groves AK, Segil N. Mammalian cochlear supporting cells can divide and trans-differentiate into hair cells. Nature 441(7096):984-987, 2006.

Woon HB, Episkopou V. Comparative expression of the mouse Sox1, Sox2 and Sox3 genes from pre-gastrulation to early somite stages. Mech. Dev. 86(1-2):197-201, 1999.

Woods C, Montcouquiol M, Kelley MW. Math1 regulates development of the sensory epithelium in the mammalian cochlea. Nat. Neurosci. 1-9, 2004.

Wu WJ, Sha SH, McLaren JD, Kawamoto K, Raphael Y, Schacht J. Aminoglycoside ototoxicity in adult CBA, C57BL and BALB mice and the Sprague-Dawley rat. Hear. Res. 158(1-2):165-178, 2001.

Yamamoto N, Tanigaki K, Tsuji M, Yabe D, Ito J, Honjo T. Inhibition of Notch/RBP-J signaling induces hair cell formation in neonate mouse cochleas. J. Mol. Med. 84(1):37-45, 2006

YAmashita H, Oesterle EC. Induction of cell proliferation in mammalian inner-ear sensory epithelia by transforming growth factor alpha and epidermal growth factor. Proc. Natl. Acad. Sci. U. S. A. 92(8):3152-3155, 1995.

ZhenG JL, GAO WQ. Analysis of rat vestibular hair cell development and regeneration using calretinin as an early marker. J. Neurosci. 17 (21):8270-8282, 1997.

Zheng JL, GAO W-Q. Overexpression of Math1 induces robust production of extra hair cells in postnatal rat inner ears. Nat. Neurosci. 3:580-586, 2000.

Zheng JL, Keller G, GaO WQ. Immunocytochemical and morphological evidence for intracellular self-repair as an important contributor to mammalian hair cell recovery. J. Neurosci. 19 (6):2161-2170, 1999.

ZINE A, DE RIBAUPIERRE F. Replacement of mammalian auditory hair cells. Neuroreport 9(2):263-268, 1998.

Zine A, DE RibaupierRe F. Notch/Notch ligands and Math1 expression patterns in the organ of Corti of wild-type and Hes1 and Hes5 mutant mice. Hear. Res. 170(1-2):22-31, 2002

Zine A, Van De Water TR, DE Ribaupierre F. Notch signaling regulates the pattern of auditory hair cell differentiation in mammals. Development 127(15):3373-3383, 2000. 